\title{
11
}

met 2

.

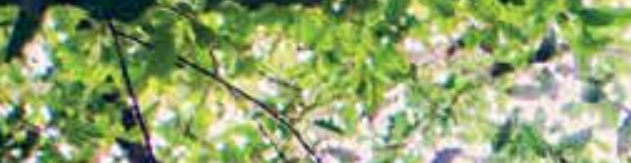

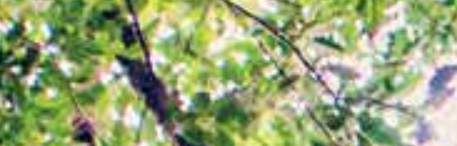

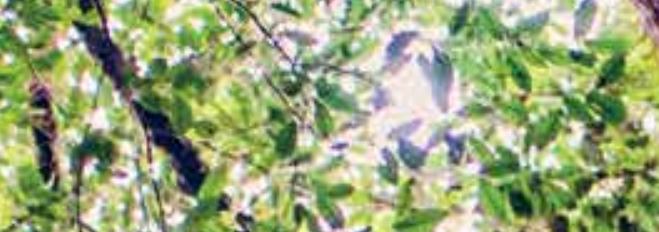

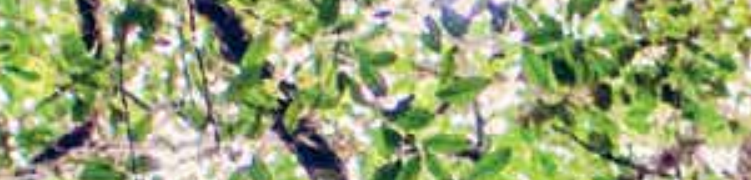

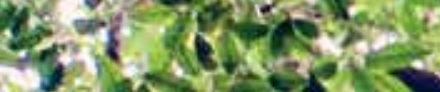

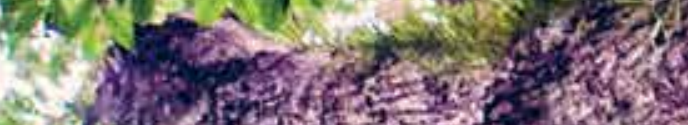

test

axis.

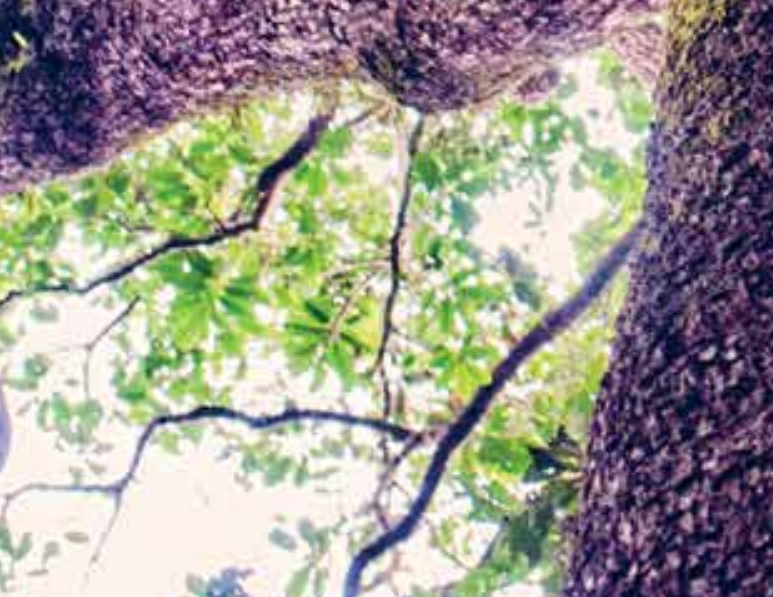

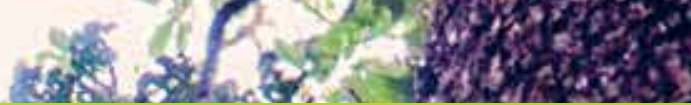
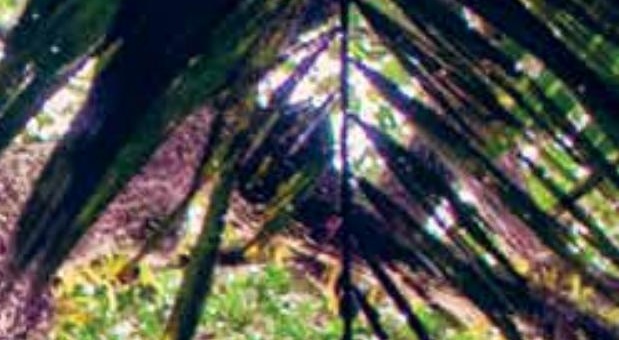

$42^{2}$

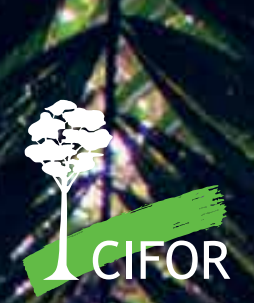

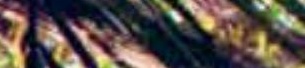

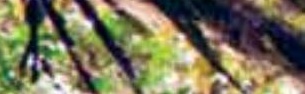

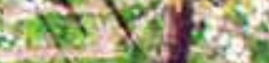

\section{Oportunidades y precondiciones para la implementación y el desarrollo de sistemas de MRV de USCUSS y REDD+ en el Perú: resumen ejecutivo}

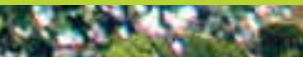





\section{Oportunidades y precondiciones para la implementación y el desarrollo de sistemas de MRV de USCUSS y REDD+ en el Perú: resumen ejecutivo}

Marcos Rugnitz-Tito

Mary Menton 
(c) 2014 Centro para la Investigación Forestal Internacional (CIFOR)

(c) (1)

Los contenidos de esta publicación están bajo licencia Creative Commons Attribution 4.0

International (CC BY 4.0), http://creativecommons.org/licenses/by/4.0/

ISBN: 978-602-1504-56-7

Rugnitz-Tito M y Menton M. 2014. Oportunidades y precondiciones para la implementación y el desarrollo de sistemas de MRV de USCUSS y REDD+ en el Perú. Bogor, Indonesia: CIFOR.

Foto de Marco Simola/CIFOR.

CIFOR

Jl. CIFOR, Situ Gede

Bogor Barat 16115

Indonesia

Tel.: $+62(251) 8622-622$

Fax: $+62(251) 8622-100$

Correo electrónico: cifor@cgiar.org

\section{cifor.org}

Queremos dar las gracias a todos los donantes que han apoyado esta investigación mediante sus contribuciones al Fondo CGIAR. Para ver la lista de donantes al Fondo, consulte: https://www.cgiarfund.org/FundDonors

Todas las opiniones expresadas en esta publicación son las de los autores. No representan necesariamente los puntos de vista de CIFOR, los editores, las instituciones a las que pertenecen los autores, los patrocinadores financieros ni los revisores. 


\section{Índice}

Reconocimientos $\quad$ iv

Introducción 1

1. ¿Por qué necesitamos un sistema nacional de MRV de emisiones de GEI? 1

2 Base existente para el sistema de MRV nacional 2

Acuerdos internacionales vinculantes a la conservación de los bosques y medidas de mitigación en el país 3

Legislación base para la conservación de los bosques y los servicios ecosistémicos 3

Estrategias Nacional y Regionales frente a la CMNUCC 4

Medidas Nacionales Apropiadas de Mitigación (NAMA/Perú): facilitación de acciones de MRV $\quad 4$

Fondos para la conservación de los bosques, REDD+ y MRV en el país 5

Estructura para la conservación de los bosques y mitigación del cambio climático 5

Propiedad de la tierra, gestión de los recursos ambientales en el Perú $\quad 7$

$\begin{array}{ll}\text { Derechos de uso sobre los recursos naturales renovables } & 7\end{array}$

Patrimonio Forestal Nacional $\quad 8$

Tasas y agentes de deforestación y degradación $\quad 8$

Inventarios Forestales Nacionales $\quad 11$

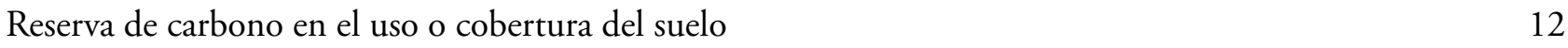

Líneas de base y escenarios futuros de referencia $\quad 12$

Emisiones de GEI asociados al uso y cambio del uso del suelo 13

$\begin{array}{ll}\text { Proyectos e iniciativas que contribuyen al MRV de bosques y a la REDD+ } & 14\end{array}$

3 Tecnologías, herramientas y sistemas de información disponibles para el MRV de REDD+ en el Perú 14

Base de información sobre recursos forestales 14

Base de información sobre estadísticas y recursos agropecuarios $\quad 15$

Base territorial $\quad 16$

Mapas temáticos regionales $\quad 16$

4 Pasos firmes en camino hacia un sistema de MRV de USCUSS y REDD+ 17

Propuesta de Sistema de Registro de Proyectos REDD+ Perú 17

Contabilidad de reducción de emisiones de GEI subnacional y nacional: enfoque anidado $\quad 18$

$\begin{array}{ll}\text { Precondiciones para el establecimiento y la manutención de un sistema de MRV de USSCUSS y } & \\ \text { REDD+ nacional y regional } & 18\end{array}$

Precondiciones metodológicas/tecnológicas $\quad 18$

$\begin{array}{ll}\text { Precondiciones de transparencia, institucionalidad y gobernanza } & 21\end{array}$

Referencias 23

\section{Lista de figuras}

1 Fases simplificadas para la implementación del mecanismo REDD+ nacional. 1

2 Niveles de categoría metodológica del IPCC. 2

3 Mapa de Ámbito de Acción del Programa de Bosques 6

4 Avances del proceso de ZEE en el Perú.

5 Mapa de Patrimonio Forestal Nacional, $2010 . \quad 8$

6 Mapa de deforestación de la Amazonía peruana al año 2000.

7 Evolución de la deforestación anual en la Amazonía peruana, periodo 2000-2011 (en hectáreas). 9

8 Deforestación en la Amazonía peruana 2009-2010-2011 (MINAM-DGOT 2013). 10

9 Mapa de concesiones mineras del Perú. 10

10 Mapa del contenido de biomasa sobre el suelo (Mg/ha) en el Perú por Baccini et al. (2012). 11

11 Mapa del contenido de biomasa sobre el suelo (Mg/ha) en el Perú por Saatchi et al. (2011). 11

12 Geografía del carbono en Perú, Asner et al 2014a 13

13 Áreas de escenarios de referencia en desarrollo en el Perú. 13 


\section{Reconocimientos}

Este estudio se inició con un primer informe elaborada por AIDER y WWF-Perú que contó con importantes aportes de Cecilia Alvarez, Daniel Arancibia, Percy Recavarren, Yanina Ratachi, y Claudia Lebel. También agradecemos a los colegas del MINAM que nos compartieron informaciones importantes al largo del estudio, en particular: Lucas Dourjeanni, Renzo Guidice, Giuliana "Cecilia” Larrea, Natalia Malaga, Giovanna Orcotoma, Laura Secada, y Brian Zutta.También agradecemos a los colegas de CIFOR que aportaron al estudio: Arief Wijaya, Miguel Pinedo-Vásquez, Amy Duchelle y Lou Verchot. Agradecemos a los financiadores del proyecto "Estudio Comparativo Global de REDD+" (GCS-REDD+) de CIFOR: la Agencia Noruega de Cooperación al Desarrollo (NORAD), la Agencia Australiana de Desarrollo Internacional (AUSAID) y el Departamento para Desarrollo Internacional del Reino Unido (DfID-UK) y la Comisión Europea (CE). 


\section{Introducción}

En el Perú, el sector de uso del suelo, cambio de uso del suelo y silvicultura (USCUSS) representa 39\% de las emisiones de gases de efecto invernadero (GEI) nacionales y la agricultura representa 20\% (MINAM 2014a). Con aproximadamente 70 millones de hectáreas de bosques y tasas de deforestación anuales de 100000 a 160000 hectáreas en las últimas décadas, el país se ha comprometido a reducir la deforestación a una tasa neta de cero en 54 millones de hectáreas de sus bosques para el año 2021, como una medida de mitigación (MINAM 2014b, Che Piu y Menton 2013). En este ámbito, con el apoyo de varias iniciativas tanto gubernamentales como de la sociedad civil, se encuentra inmerso en el proceso de preparación (readiness) para REDD+ (reducción de emisiones por deforestación y degradación y el papel de la conservación, el manejo forestal sostenible y el aumento de reservas de carbono en países en desarrollo). Como parte de la fase de preparación está el desarrollo de un sistema nacional y regional de medición, reporte y verificación (MRV) de emisiones de GEI derivados de los USCUSS a los que se pueda aplicar procesos de REDD+. Aunque todavía no existe un modelo consensuado para este sistema, las iniciativas regionales y del Gobierno nacional están encaminadas en esa dirección.

Es en este contexto que, a través del análisis del proceso nacional de preparación e implementación para REDD+ y de las actuales políticas, compromisos, plataformas y sistemas de información agroambientales, se ha desarrollado el informe Oportunidades y precondiciones para la implementación $y$ el desarrollo de sistemas de MRV de USCUSS y REDD + en el Perú. Elaborado en el marco del Estudio Comparativo Global sobre REDD+ (GCS-REDD) ${ }^{1}$, el documento presenta y relaciona las informaciones ya existentes en el país con las precondiciones necesarias para un sistema de MRV de USCUSS y REDD+ nacional que esté en armonía con las iniciativas y sistemas regionales.
Este documento presenta un resumen ejecutivo de los cuatro capítulos del informe. El informe completo es de libre acceso y se encuentra disponible en cifor.org/ library.

\section{1. ¿Por qué necesitamos un sistema nacional de MRV de emisiones de GEI?}

Como integrante de programas internacionales como FCPF (Forest Carbon Partnership Facility), ONU-REDD (Programa REDD+ de las Naciones Unidadas) y FIP (Forest Investment Plan), y de la Convención Marco de Naciones Unidas sobre el Clima, el Gobierno peruano debe demostrar que tiene las condiciones necesarias para la reducción de las emisiones de GEI, a lo que se comprometió durante la XV Conferencia de las Partes (COP15) realizada en Copenhague (Dinamarca). Para esto, el sistema de MRV permitirá evaluar y determinar el stock de carbono de todos los usos del suelo, así como calcular las emisiones provenientes del cambio de uso (deforestación) y del proceso de degradación de los boques, entre otros sectores. Más allá de los compromisos internacionales, el Perú tiene un compromiso interno de uso racional de los bosques (y, en consecuencia, de reducción de las emisiones de GEI).

De acuerdo con las propuestas presentadas por diversos actores, el Ministerio del Ambiente (MINAM) debe seguir el ejemplo de otros países e implementar el mecanismo REDD+ nacional en tres fases: (i) Fase 1 de preparación (también conocida por el término en inglés readiness), (ii) Fase 2 de establecimiento de políticas y medidas que posibilitan REDD+; y (iii) Fase 3 de pago por resultados. Según el comité de The Forests Dialogue (TFD 2009), un enfoque de implementación por fases permite a REDD+ abordar las causas de la deforestación a nivel nacional de acuerdo con las circunstancias específicas de cada país.

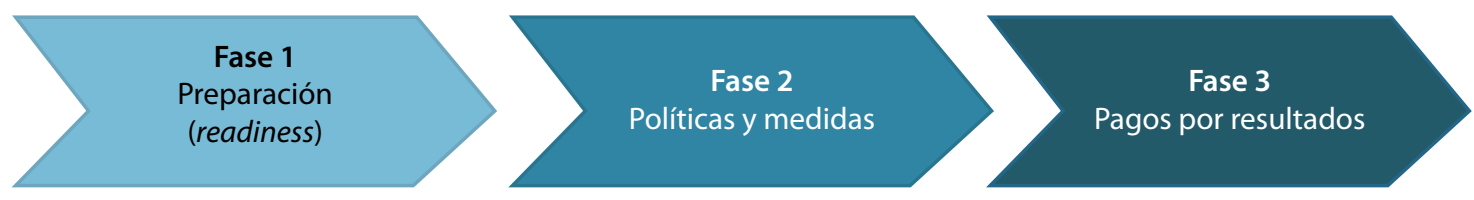

Figura 1. Fases simplificadas para la implementación del mecanismo REDD+ nacional.

1 Para más información, consultar: <http://www. forestsclimatechange.org/global-comparative-study-onredd.html>. 
El Perú optó por la adopción de una estrategia nacional para REDD+ a partir de un enfoque anidado (nested approach), por considerar que es la opción más apropiada y consistente con su realidad nacional (MINAM 2011a). De acuerdo con lo expuesto en la RPP (Propuesta del Plan de Readiness) de 2013, el enfoque anidado permite al país iniciar la implementación de REDD+ a nivel subnacional (local y/o regional) y crecer hacia el nivel nacional a medida que aumenten las capacidades en el país para diseñar, implementar, monitorear, verificar y reportar iniciativas de REDD + a todos los niveles. Inicialmente, las reducciones de emisiones se reportarían únicamente para iniciativas en el nivel local; luego, para iniciativas en los niveles locales y regionales; y finalmente, a todos los niveles (MINAM 2013).

Los avances en las mediciones de las emisiones de GEI por el sector USCUSS también se registrarán por niveles o en un enfoque escalonado (stepwise approach), lo que implica que se iniciarán con una precisión de Nivel 1 (Tier 1) y el uso de factores de emisión del Panel Intergubernamental de Cambio Climático (IPCC), e irán mejorando la disponibilidad de datos para crear factores de emisiones nacionales que permitan llegar al Nivel 2 (Tier 2) y el Nivel 3 (Tier 3).

A los proponentes de iniciativas de REDD+ subnacionales (locales y regionales), el enfoque por niveles les permite proponer y registrar a nivel nacional sus proyectos y programas, pasando por un proceso institucionalizado de revisión, aprobación y registro de sus iniciativas. $\mathrm{Al}$ estar registradas las iniciativas subnacionales, tendrían el derecho de comercializar las reducciones de emisiones verificadas que se vayan generando dentro de sus ámbitos territoriales. En este sentido, el enfoque anidado permite que iniciativas subnacionales estén en la Fase 3 de REDD+ aún cuando el nivel nacional se encuentre todavía en la Fase 1 (readiness) o en la Fase 2 (políticas y medidas). Sin embargo, al mismo tiempo que posibilita el desarrollo de iniciativas tempranas, esta situación ha dificultado el entendimiento por parte de los actores locales de la estrategia REDD+ propuesta y ha creado grandes retos de armonización de escenarios regionales con el escenario nacional..

\section{Base existente para el sistema de MRV nacional}

En los últimos años, se dieron en el Perú avances importantes en la institucionalidad ambiental, que contribuyeron al cumplimiento de los objetivos prioritarios y las acciones estratégicas contenidos en el Plan Nacional de Acción Ambiental (PLANAA); principalmente, el surgimiento de muchas iniciativas de pago por servicios ambientales (PSA), mecanismo

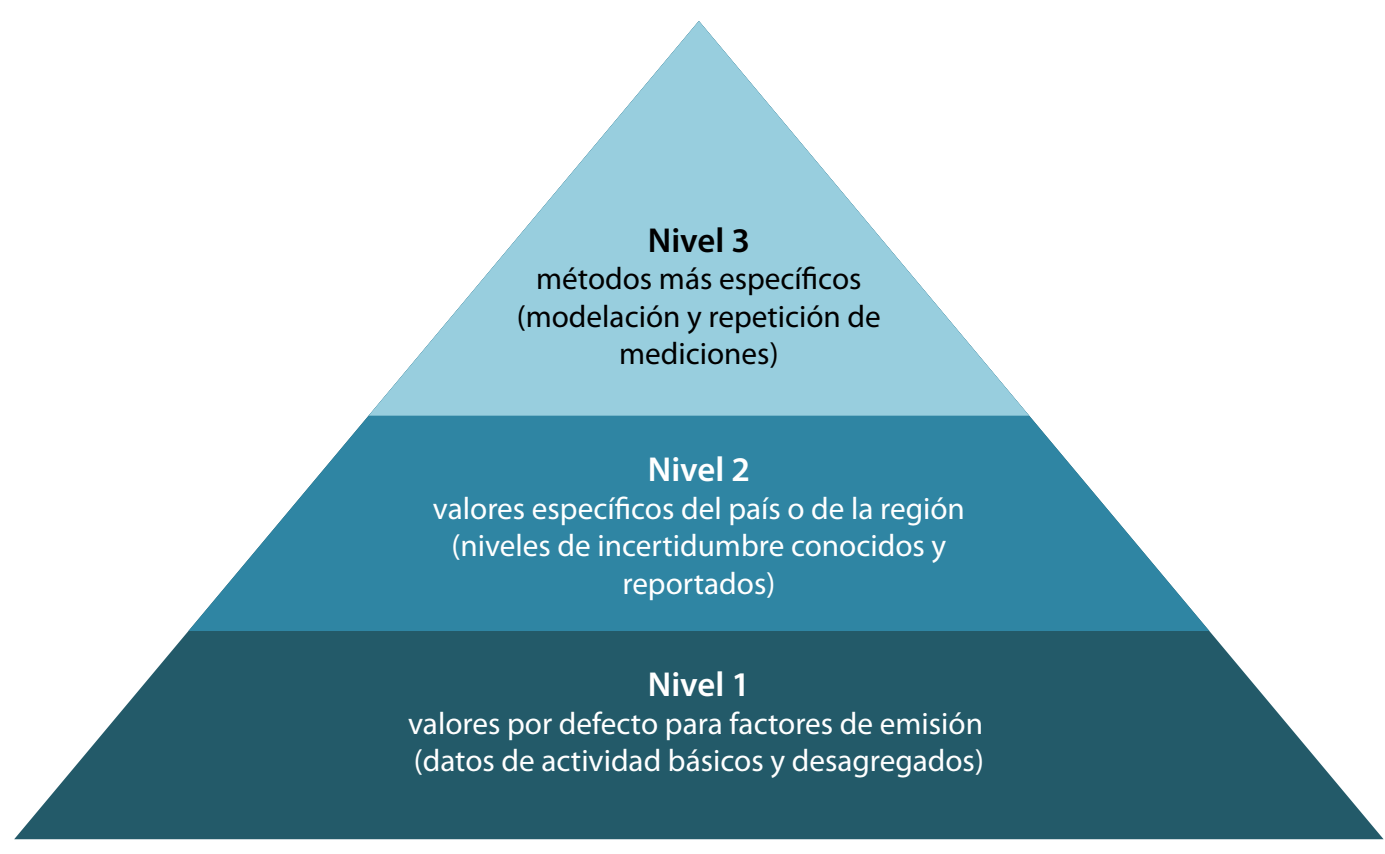

Figura 2. Niveles de categoría metodológica del IPCC. 
creado para reducir la deforestación y promover la conservación y el uso sostenible. También se produjo el inicio de la preparación para el desarrollo de salvaguardas socioambientales para REDD+, con contribuciones activas por parte de la sociedad civil. Estas salvaguardas buscan asegurar que las medidas y políticas de REDD+ disminuyan los impactos socioambientales que provienen de la implementación de este tipo de iniciativas. Para ello, el Perú apoya el establecimiento de un acuerdo político y técnico para definir un mecanismo de REDD+ como un complemento a las iniciativas nacionales y subnacionales, que esté de acuerdo con las políticas y normas existentes, así como con los recursos disponibles. Esto se resume en las secciones siguientes.

\section{Acuerdos internacionales vinculantes a la conservación de los bosques y medidas de mitigación en el país}

Desde 1970, el Perú ha firmado y ratificado varios tratados y acuerdos internacionales (multi o bilaterales), comprometiéndose a conservar el patrimonio natural dentro de sus fronteras. Entre otros, se destacan los de RAMSAR (Convención Relativa a los Humedales de Importancia Internacional, especialmente como Hábitat de Aves Acuáticas), CITES (Convención sobre el Comercio Internacional de Especies Amenazadas de Fauna y Flora Silvestres), CBD (Convenio sobre la Diversidad Biológica), el Protocolo de Kioto, y la CMNUCC (Convención Marco de las Naciones Unidas sobre el Cambio Climático). Estos acuerdos socioambientales internacionales tienen relación directa con la formulación y ejecución de la legislación nacional, así como con el desarrollo y aplicación de un sistema de MRV de REDD+ nacional. Ello debido a que, entre otras acciones, ayudan a la definición de las competencias ambientales, establecen directrices para el uso sostenible de los recursos, priorizan áreas para la conservación y evidencian la importancia de los servicios ecosistémicos.

\section{Legislación base para la conservación de los bosques y los servicios ecosistémicos}

De acuerdo con la Constitución Política nacional, es de responsabilidad del Estado garantizar el buen uso de los recursos naturales y servicios ecosistémicos, al otorgar (conceder) derechos de uso a particulares para que se beneficien económicamente con los frutos que obtengan de la explotación de ese recurso o servicio, o declarar la caducidad de dichos derechos otorgados en caso de mal uso. De acuerdo con el D. S. 0172009-AG, las tierras que tienen la designación de "uso mayor" de bosque solo pueden ser deforestadas si ello es de interés nacional. Sin embargo, en la práctica no se ha seguido una política tan restringida de cambio de "uso mayor".

Cabe resaltar que con la promulgación de la nueva Ley Forestal (Ley 29763) y de leyes como la Ley Orgánica de Gobiernos Regionales (Ley 27867) y la Ley Orgánica de Municipalidades (Ley 27972), el Gobierno peruano viene indicando que busca fortalecer la gobernabilidad y la gobernanza ambiental/forestal en las distintas regiones del país. Sin embargo, el proceso de descentralización todavía no está concluido. En muchos casos, aunque la autoridad para la gobernanza ya ha sido transferida por ley, los Gobiernos y las autoridades regionales aún no tienen la capacidad técnica y financiera para su implementación efectiva.

El debate sobre la permisibilidad de negociar servicios ecosistémicos y ambientales en el país, tema también relacionado con la posibilidad de desarrollar iniciativas de REDD+ (y co-beneficios), volvió a ganar fuerza con la aprobación (el 10 de diciembre de 2013), por la Comisión de Pueblos Andinos, Amazónicos y Afroperuanos y Ambiente y Ecología, del texto sustitutorio (a los proyectos de ley 786/2011-CR², 1755/2012-CR y 2629/2013$\left.\mathrm{CR}^{4}\right)$ que reglamenta la Ley de Mecanismos de Retribución por Servicios Ecosistémicos. En febrero de 2014, se aprobó la Directiva General 001-20142014, que afirma los derechos a la comercialización de servicios ecosistemicos (incluyendo el carbono) en áreas naturales protegidas (ANP). Esta dicta que el SERNANP (Servicio Nacional de Áreas Naturales Protegidas por el Estado) mantiene la titularidad a los certificados de carbono u otros servicios

2 Proyecto de ley de provisión de servicios ambientales, presentado el 31 de enero de 2012 por el congresista César Yrupailla Montes.

3 Proyecto de ley que regula el pago de los servicios ambientales y establece mecanismos para su promoción, presentado el 27 de noviembre de 2012 por el congresista Teófilo Gamarra Saldívar.

4 Proyecto de ley de compensación por servicios ambientales, presentado el 5 de septiembre de 2013 por el congresista Néstor Valqui Matos. 
ecosistémicos, pero que puede transferir a terceros la potestad de comercializarlos. En junio de 2014, el Congreso peruano aprobó por unanimidad la Ley de Mecanismos de Retribución por Servicios Ecosistémicos, que dicta los reglamentos para el PSA, tanto para carbono como para recursos hídricos y otros servicios ambientales.

\section{Estrategias Nacional y Regionales frente a la CMNUCC}

Como uno de los países signatarios de la Convención del Clima (CMNUCC), el Perú tienen el compromiso de elaborar, actualizar y presentar periódicamente (i) los inventarios nacionales de emisiones antropogénicas de GEI; así como (ii) la propuesta de acciones de mitigación. Estas informaciones fueron presentadas a la CMNUCC por medio de la "Comunicación Nacional sobre Cambio Climático” en 2001 y 2010.

La primera Estrategia Nacional de Cambio Climático (ENCC) fue elaborada en 2003. La segunda ENCC de 2014 reconoce que el principal reto para el Perú es la reducción del riesgo asociado al cambio climático y la realización de acciones para la adaptación del país y reducción de la vulnerabilidad (MINAM 2014a). También destaca el objetivo de "fortalecer la gobernanza y la gobernabilidad forestal para fines de reducir las emisiones de GEI" y reitera su compromiso de reducir la tasa de deforestación a cero en 54 millones de ha (MINAM 2014a, p. 46). En enero de 2014, la iniciativa del PNCBMCC se elaboraron los lineamientos de la Estrategia de Bosques y Cambio Climático, la cual MINAM y MINAGRI presentarán en la COP20.

A nivel regional, la Ley Orgánica de Gobiernos Regionales (Ley 27867) dispone que cada Gobierno regional elabore su propia estrategia regional de cambio climático (ERCC). Las estrategias regionales de cambio climático deben elaborarse en el marco de la estrategia a nivel nacional, pero deben contemplar la propia realidad regional. A la fecha, las regiones de Junín (2007); Amazonas (2008); Lambayeque y Arequipa (2010); Ayacucho, Loreto y Piura (2011); y Cusco (2012) han aprobado sus ERCC. Otras regiones, como Apurímac, Lima, La Libertad, Tacna y Tumbes, cuentan con una propuesta de estrategia para aprobación. Y un tercer grupo, compuesto por regiones como Áncash, Cajamarca, Ica, Huancavelica, Huánuco, Ucayali y Moquegua, se encuentran en proceso de formulación de sus estrategias (portal Cambio Climático 2014)5.

\section{Medidas Nacionales Apropiadas de Mitigación (NAMA/Perú): facilitación de acciones de MRV}

Como parte de los Acuerdos de Cancún (COP 16), los países en desarrollo contribuirán a la mitigación del cambio climático a través de Medidas Nacionales Apropiadas de Mitigación (NAMA), que recibirán financiamiento y soporte tecnológico de los países industrializados. El Meridian Institute (2009) considera que un modelo de registro REDD+l NAMA puede facilitar el rastreo y coordinación de las fuentes de financiamiento y el MRV de acciones y apoyo. Según la misma institución, este tipo de registro brindaría transparencia y colaboraría para garantizar la integridad de las acciones de REDD+y el apoyo bilateral.

Para el MINAM (2010b), las NAMA combinan acciones y programas que pueden ser ejecutados como proyectos de MDL (mecanismo de desarrollo limpio), proyectos con apoyo externo adicional o proyectos que el país realiza por su cuenta como una contribución a la mitigación global. Estos proyectos deben ser coordinados por el MINAM y/o el ministerio de la cartera respectiva bajo un sistema de registro y contabilidad de las acciones y reducciones, que permita a terceros la verificación de dichas reducciones, aun cuando no formen parte de los compromisos nacionales cuantificables, sino como metas voluntarias y verificables.

Dos planes nacionales contribuyen más directamente con las NAMA: (i) el Plan de Acción de Adaptación y Mitigación frente al Cambio Climático (PAAMCC) ${ }^{6}$ y (ii) el Plan Nacional de Acción Ambiental (PLANAA).

El PAAMCC de 2010 describe la propuesta del MINAM para programas, proyectos y acciones prioritarias de corto y mediano plazo en relación

\footnotetext{
5 Disponible en: <http://cambioclimatico.minam.gob.pe/lagestion-del-cc/avances-en-la-planificacion-regional/>.

6 Plan aprobado mediante Resolución Ministerial 238-2010-MINAM y publicado en el diario oficial El Peruano el 2 de diciembre. Disponible en $:<$ http://cambioclimatico.minam. gob.pe/plan-de-accion-de-adaptacion-y-mitigacion-frente-alcambio-climatico/>.
} 
con el cambio climático. El Plan registra y analiza 68 proyectos, programas e iniciativas de adaptación y mitigación al cambio climático, organizados en siete líneas temáticas, tres de ellas potencialmente relacionadas con el desarrollo de sistemas de MRV (nacional y regionales): (i) cuantificación de las emisiones de GEI mediante sistemas de reporte y verificación de la información; (ii) fortalecimiento de los sistemas de vigilancia del clima e investigación; (iii) gestión del financiamiento: integración y alineación de las necesidades logísticas y técnicas del Estado para optimizar el uso de los escasos recursos.

También elaborado por el MINAM, el PLANAA propone siete acciones estratégicas para su implementación en el periodo 2012-2021. Entre estas se encuentran el desarrollo y aplicación de estrategias regionales y locales de mitigación del cambio climático.

\section{Fondos para la conservación de los bosques, REDD+ y MRV en el país}

En el Perú, se encuentran en marcha una serie de acciones que contribuyen a la lucha contra la deforestación (MINAM 2012b), en parte financiadas por cooperantes y fondos internacionales. Entre otras actividades, los recursos están siendo utilizados principalmente para: (i) fortalecimiento de capacidades; (ii) mapeo, medición y monitoreo de los recursos forestales y las emisiones de GEI; iniciativas de compensación por servicios ambientales (p. ej.: Programa Nacional de Conservación de Bosques); (iii) conservación de bosques; y (iv) gobernanza forestal.

Para esta fase de preparación/readiness, el Perú recibe financiamiento y apoyo del FCPF. Para acceder al FCPF, los países, entre otros requerimientos, deben elaborar una propuesta para su plan de preparación (RPP). La primera versión de la RPP fue presentada en marzo de 2011. Más recientemente, en diciembre de 2013, fue presentada una nueva versión. Una vez aprobada, el próximo paso debe ser la implementación del Paquete de Preparación (R-Package), que debe contener el conjunto de actividades diseñadas para soportar las capacidades necesarias para participar en futuros sistemas de incentivos positivos para REDD+. Estas incluyen un escenario de referencia, una estrategia de REDD+ y un sistema de MRV. Adicionalmente, los países deben someter un ER-PIN (Nota de Concepto del Programa de Reducción de Emisiones), lo cual Perú sometió al FCPF en mayo de 2014 (MINAM 2014b).

Parte de los recursos actualmente se destinan a la fase de preparación de REDD+. Según la RPP de 2013, el presupuesto para la fase de preparación es de US\$12.145.000, con US\$ 505.000 para el desarrollo del escenario de referencia, US\$ 6.412.000 para el desarrollo del sistema nacional de monitoreo forestal y salvaguardas, y US\$288.000 para el diseño del marco de evaluación y monitoreo. Se tiene asegurado un aproximado de US\$ 13 millones para esta fase, y se esperan entre US\$30 y 50 millones comprometidos (del FIP) para la fase de implementación (MINAM 2013). Según el REDDX de Forest Trends ${ }^{7}$, hasta el año 2012, sin contar con el FIP, el Perú recibió compromisos de financiamiento por US\$28 millones, con $61 \%$ dirigido a la sociedad civil y el sector privado.

En 2012, el proyecto financiado por el Banco Alemán de Desarrollo KfW ("Apoyo a la implementación de REDD+ en el Perú") ha sido unificado con el proyecto financiado por la Fundación Gordon \& Betty Moore ("Fortalecimiento de capacidades técnicas, científicas e institucionales para la implementación de REDD+ en el Perú”). Juntos representan una inversión en el país de US\$ 10,5 millones bajo el Proyecto REDD+ MINAM. Entre las iniciativas del Proyecto REDD+ MINAM se encuentran el componente de "Desarrollo de marcos metodológicos estandarizados (MME) para escenarios de referencia y MRV" y el componente de "Desarrollo de líneas de base regionales". El Proyecto REDD+ MINAM busca cofinanciar la RPP en el desarrollo de capacidades institucionales, legales y técnicas del MINAM y otras instituciones relevantes involucradas con el desarrollo de metodologías de MRV a escala nacional y subnacional (RPP versión 2013).

\section{Estructura para la conservación de los bosques y mitigación del cambio climático}

Entre los principales sistemas y programas para la conservación de los bosques y mitigación del cambio

7 Disponible en: <http://reddx.forest-trends.org/country/peru/ overview>. 
climático en operaciones en el país, destacan el Sistema Nacional de Gestión Ambiental (SNGA), el Sistema Nacional de Evaluación de Impacto Ambiental (SEIA) y el Programa Nacional de Conservación de Bosques para la Mitigación del Cambio Climático (PNCBMCC).

Establecido en 2004 (Ley 28245), el SNGA integra los sistemas de gestión ambiental, tales como los sistemas sectoriales, transectoriales y territoriales. El MINAM es el ente rector, a través de la Dirección General de Políticas, Normas e Instrumentos de Gestión Ambiental (DGPNIGA). El SNGA fue constituido sobre las bases de los sistemas de información ambiental nacional, regionales y locales (artículo 14.2, Ley 28611).

El Sistema Nacional de Información Ambiental $(\text { SINIA })^{8}$ organiza la información sobre la base de indicadores ambientales que ayudan a presentar el estado del ambiente a nivel nacional. El SINIA está conformado por los sistemas de información ambiental regionales (SIAR) y sistemas de información ambiental locales (SIAL). El proceso de coordinación para la implementación de los SIAR y SIAL a nivel nacional recae en la Dirección General de Investigación e Información Ambiental del Viceministerio de Gestión Ambiental. El proceso de implementación de los SIAR/SIAL sigue cinco pasos, el último de los cuales es el monitoreo permanente de los componentes y tipos de información de los SIAR, en especial de los indicadores ambientales, que deben cumplir con criterios de calidad (EFC 2011).

Entre los indicadores ambientales monitoreados pueden estar los índices de deforestación, de degradación, de biomasa presente en la vegetación y de usos del suelo de la región; conformando así un sistema regional de MRV de USCUSS y GEI.

Además de la estructura de los SIAR/SIAL, fue creado el Sistema Nacional de Evaluación de Impacto Ambiental, reglamentado en 2009 (D. S. 019-2009-MINAM). El Ministerio del Ambiente también es el ente encargado de dirigir y administrar el sistema y asegurar su carácter transectorial. Entre otros, el SEIA establece los planes de manejo ambiental (PM) y de cierre o abandono, que pueden ser utilizados para alimentar un sistema de MRV regional.

8 http://sinia.minam.gob.pe

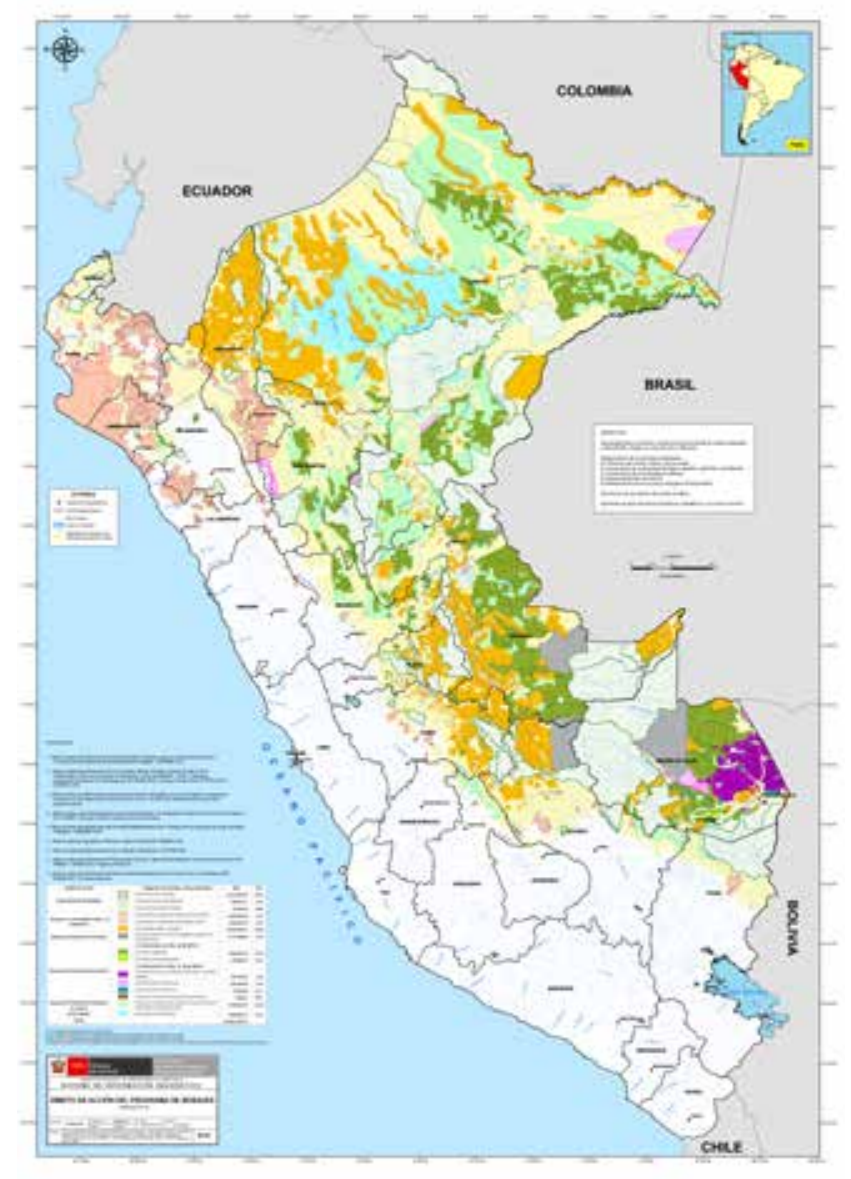

Figura 3. Mapa de Ámbito de Acción del Programa de Bosques

Fuente: MINAM 2010

a Disponible en: < http://geoservidor.minam.gob. pe/geoservidor/Archivos/Mapa/N01_PROGRAMA_ BOSQUES_2010.pdf >.

Creado mediante D. S. 008-2010-MINAM, el PNCBMCC es considerado un programa "sombrilla" que busca abarcar las actividades del Gobierno relacionadas con la reducción de la deforestación como contribución voluntaria del país a los esfuerzos globales de mitigación del cambio climático (Figura 3). Tiene como objetivo conservar 54 millones de hectáreas y reducir la tala anual de 100.000 hectáreas en 2009 a una tasa neta de cero hectáreas de bosques primarios o naturales para el año 2021. Para cumplir con su objetivo, se organiza en cuatro componentes, el primero de los cuales implementará un sistema de monitoreo del USCUSS en períodos anuales para los bosques comunales sujetos a las TDC (Transferencias Directas Condicionadas) y cada dos años para el nivel nacional. 


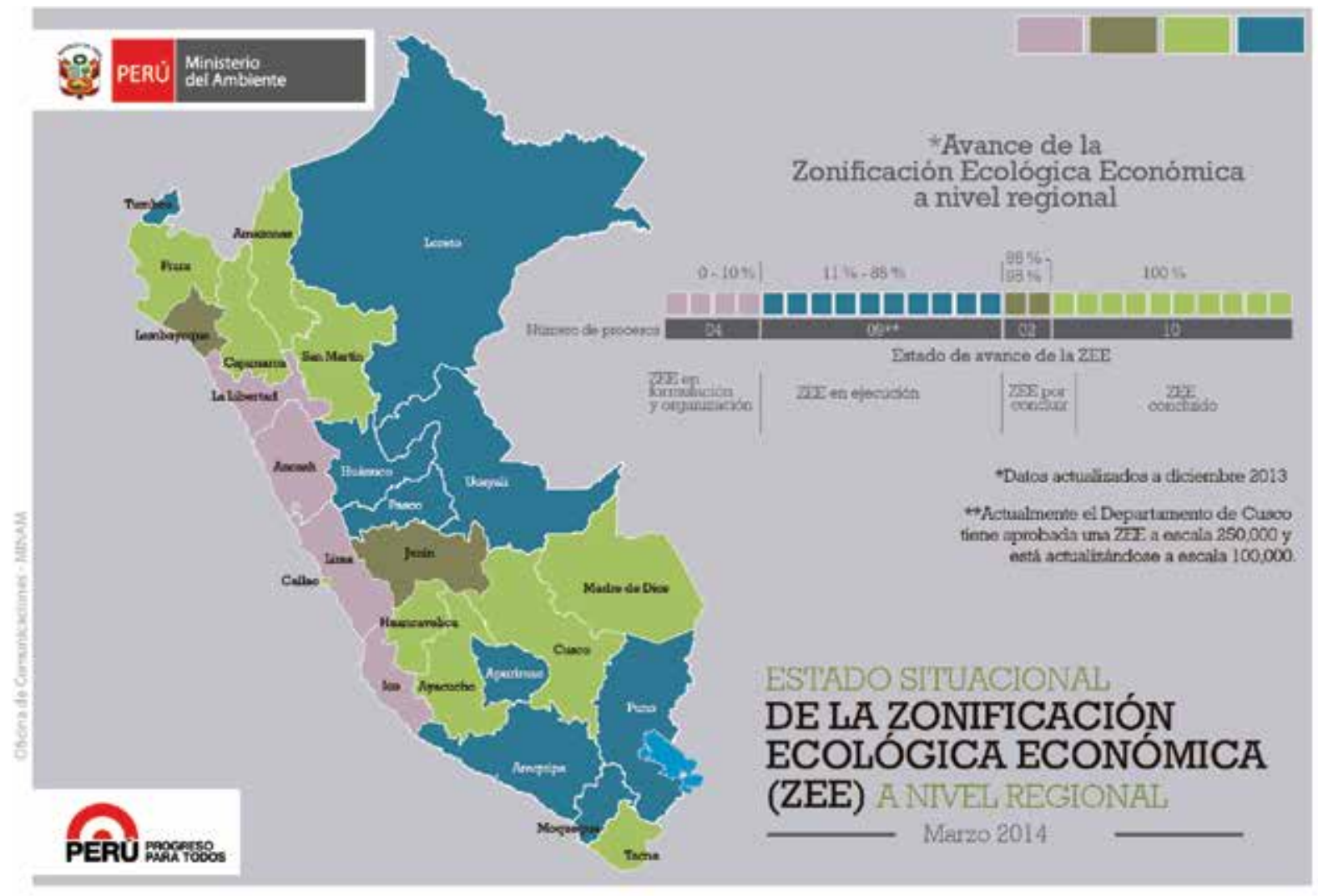

Figura 4. Avances del proceso de ZEE en el Perú.

Fuente: MINAM 2014c

\section{Propiedad de la tierra, gestión de los recursos ambientales en el Perú}

El país aún no cuenta con una ley específica de ordenamiento territorial (se encuentra en proceso de elaboración) que determine los lineamientos necesarios para el uso adecuado de la tierra en el país. Sin embargo, sí cuenta con algunas normativas relacionadas con el tema, como la Ley Orgánica de los Gobiernos Regionales (Ley 27867/03) y la Ley Orgánica de Municipalidades (Ley 27972/03). Actualmente, el ordenamiento territorial se efectúa sobre la base de la Zonificación Ecológica Económica (ZEE), que permite conocer las potencialidades y limitaciones para el uso del suelo (Asencio Díaz 2010). El MINAM, en su condición de Autoridad Ambiental Nacional, dirige el proceso de gestión de la ZEE (D. S. 087-2004PCM), bajo la responsabilidad de la Dirección General de Ordenamiento Territorial (D. L. 1013). En el año 2004, mediante la Ley Orgánica de los Gobiernos Regionales (Ley 27867), se les otorgó a los Gobiernos regionales las funciones de formular, aprobar, ejecutar, evaluar, dirigir, controlar y administrar los planes y políticas en materia ambiental y de ordenamiento territorial de su jurisdicción, por lo que son los encargados de elaborar la ZEE para su región.

En el III Plan Operativo Bienal de Ordenamiento Territorial (2011-2013) se han inscrito 21 procesos regionales. De ellos, 7 se desarrollan a nivel de macrozonificación; 12 se desarrollan a nivel de mesozonificación; 1 combina los niveles macro y meso; y 1 se desarrolla a nivel de microzonificación. Asimismo, existen 15 procesos provinciales, de los cuales 12 se desarrollan a nivel de mesozonificación; 2 se desarrollan a nivel de microzonificación; y 1 proceso combina las escalas micro y meso. Estos procesos de ZEE siguen en marcha (Figura 4).

\section{Derechos de uso sobre los recursos naturales renovables}

La nueva Ley Forestal y de Fauna Silvestre (Ley 29763), de julio de 2011, establece como modelo de acceso y aprovechamiento del bosque el otorgamiento de concesiones forestales en bosques de producción permanente previamente determinados como parte del ordenamiento forestal del país. Las concesiones 
forestales con fines maderables y no maderables son otorgadas por la autoridad forestal y de fauna silvestre al sector privado, para el aprovechamiento de los recursos forestales mediante planes de manejo forestal sostenible. La nueva Ley Forestal señala que el Servicio Nacional Forestal y de Fauna Silvestre (SERFOR), adscrito al Ministerio de Agricultura y Riego (MINAGRI), es responsable, entre otras tareas, de fiscalizar el cumplimiento de las obligaciones de los derechos otorgados bajo su competencia y sancionar las infracciones derivadas de su incumplimiento, respetando las competencias del Organismo de Supervisión de los Recursos Forestales y de Fauna Silvestre (OSINFOR), el Organismo de Evaluación y Fiscalización Ambiental (OEFA), los Gobiernos regionales y locales, y otros organismos públicos. Cabe destacar que a partir de la Ley Orgánica de Gobiernos Regionales y el proceso de descentralización, las competencias forestales fueron transferidas desde el Gobierno central a los Gobiernos regionales.

\section{Patrimonio Forestal Nacional}

De acuerdo con la Constitución del Perú, los bosques son Patrimonio de la Nación y el Estado es el responsable de su administración y de promover su conservación y aprovechamiento sostenible. Los recursos forestales y de fauna silvestre que integran el Patrimonio Forestal Nacional no pueden ser utilizados con fines agropecuarios o para otras actividades que afecten la cobertura vegetal, el uso sostenible y la conservación del recurso forestal, salvo en los casos que señalen la Ley Forestal y de Fauna Silvestre y su reglamento (artículo 7, Ley 27308). Sin embargo, los bosques del Perú no han pasado por un proceso integral de zonificación, ordenamiento, inventario y valorización; los datos se encuentran desactualizados y se carece de un catastro adecuado de usos y derechos sobre el bosque (Capella y Sandoval 2009).

Diversos estudios han tratado de establecer estadísticas, mapas y clasificaciones asociadas a la cobertura vegetal para determinar los límites de las formaciones de bosque en el país. El Mapa del Patrimonio Forestal Nacional (MPFN) más reciente fue elaborado en 2010 por la Dirección General de Evaluación, Valoración y Financiamiento del Patrimonio Natural (DGEVFPN) del MINAM. Según el mapa (Figura 5), el patrimonio forestal actual posee una superficie de 114.300 .530 hectáreas (MINAM 2010c). A partir de la información base generada para la construcción del MPFN fueron

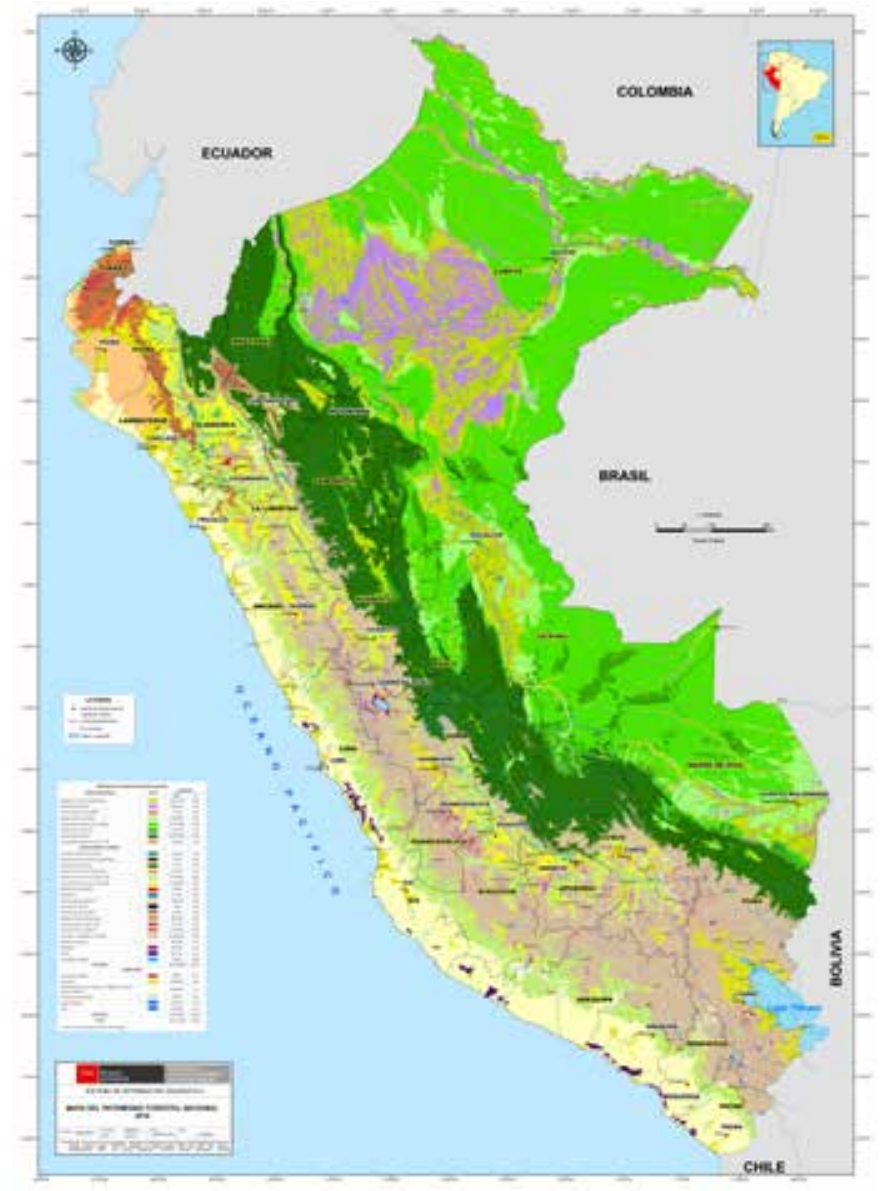

Figura 5. Mapa de Patrimonio Forestal Nacional, 2010. Fuente: MINAM 2010c.

generados mapas por tipos de bosques, como humedales, bosques relictos y secos, pajonales altoandinos, entre otros. De acuerdo con la misma entidad, próximamente se incluirán en el MPFN las áreas deforestadas de la Amazonía para obtener la superficie neta de los bosques amazónicos.

Según los resultados de mapeo del Proyecto REDD+ MINAM, la cobertura forestal en la Amazonía en 2011 fue de apenas 69,6 millones de hectáreas (MINAM 2014d).

\section{Tasas y agentes de deforestación y degradación}

Desde 1975, se vienen realizando algunos esfuerzos para determinar la deforestación a nivel local y nacional. Los estudios existentes presentan tasas de deforestación que varían drásticamente, dando lugar a resultados contradictorios, lo que demuestra una fuerte inconsistencia de la información y amerita estudios mucho más exhaustivos (Linares 2011, 
Che Piu y Menton 2013). Los principales registros referentes a la evolución de la deforestación en el país son los siguientes:

- Mapa de deforestación de la Amazonía peruana, 2000, Proyecto PROCLIM, MINAG (2009)

(Figura 6).

- Cobertura de bosque y deforestación 2000-2009 MINAM-DGOT (2012).

- Cambio de cobertura de bosque a no bosque por deforestación en la Amazonía peruana en el periodo 2009-2010-2011, MINAM-DGOT (2013) (Figura 8).

- Perdida de los bosques húmedos del Perú de 2000-2011, MINAM-PNCB (2014) (Figura 7).

Según el MINAM (2014d), en el periodo 20002011 el país ha perdido 1.172.645 hectáreas de la cobertura vegetal de la Amazonía. Como se aprecia en la figura 7, en este periodo hubo una tendencia creciente de la deforestación en el país, que alcanzó su nivel máximo en el año 2009.

Aunque no son parte del MRV actualmente, los sistemas de alerta temprana también son relevantes para REDD+. El sistema de Terra-i (http:// www.terra-i.org/terra-i.html), una colaboración entre MINAM y el Centro Internacional para la Agricultura Tropical (CIAT) detecta cambios de la cobertura vegetal y sirve como un sistema de altera temprana de cambios de uso de la tierra. Junto con datos sobre cambios de cobertura de

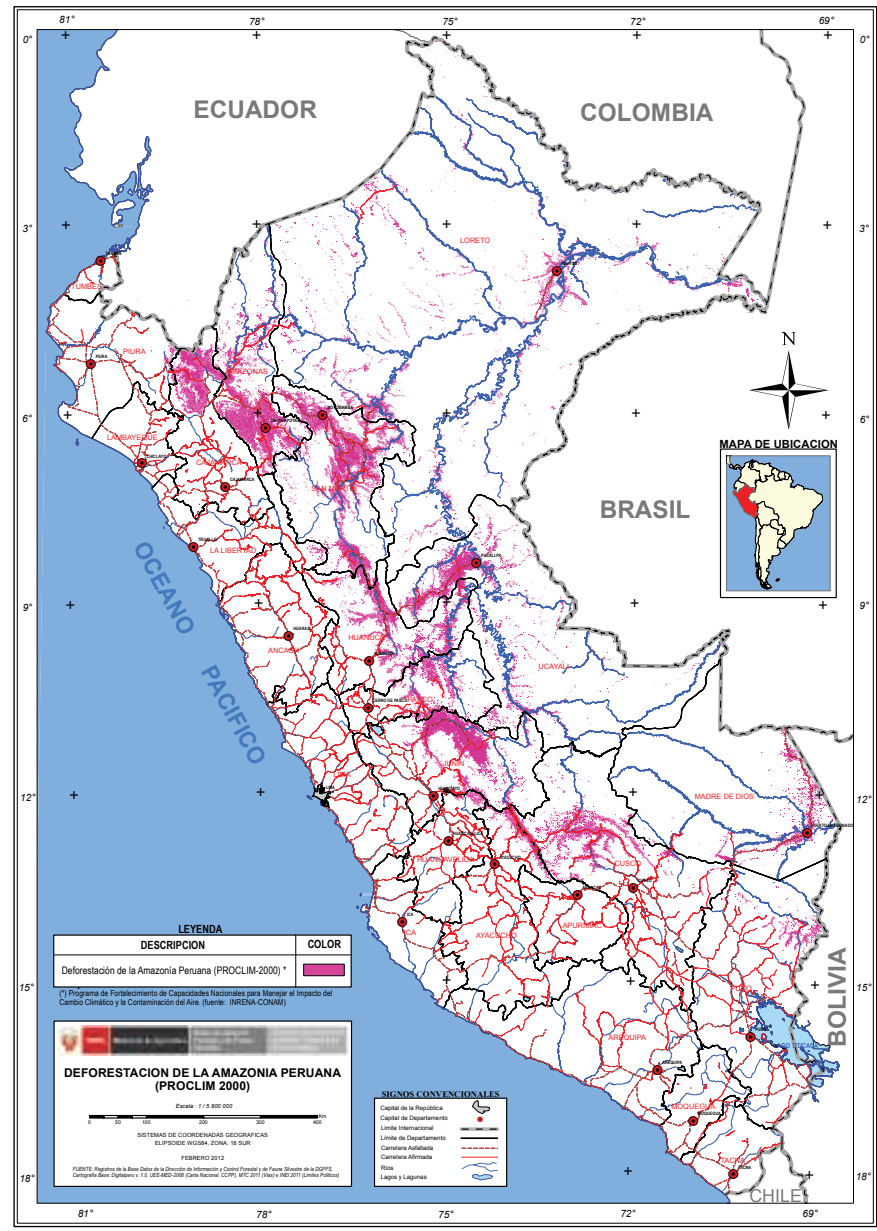

Figura 6. Mapa de deforestación de la Amazonía peruana al año 2000.

Fuente: MINAG (2009).

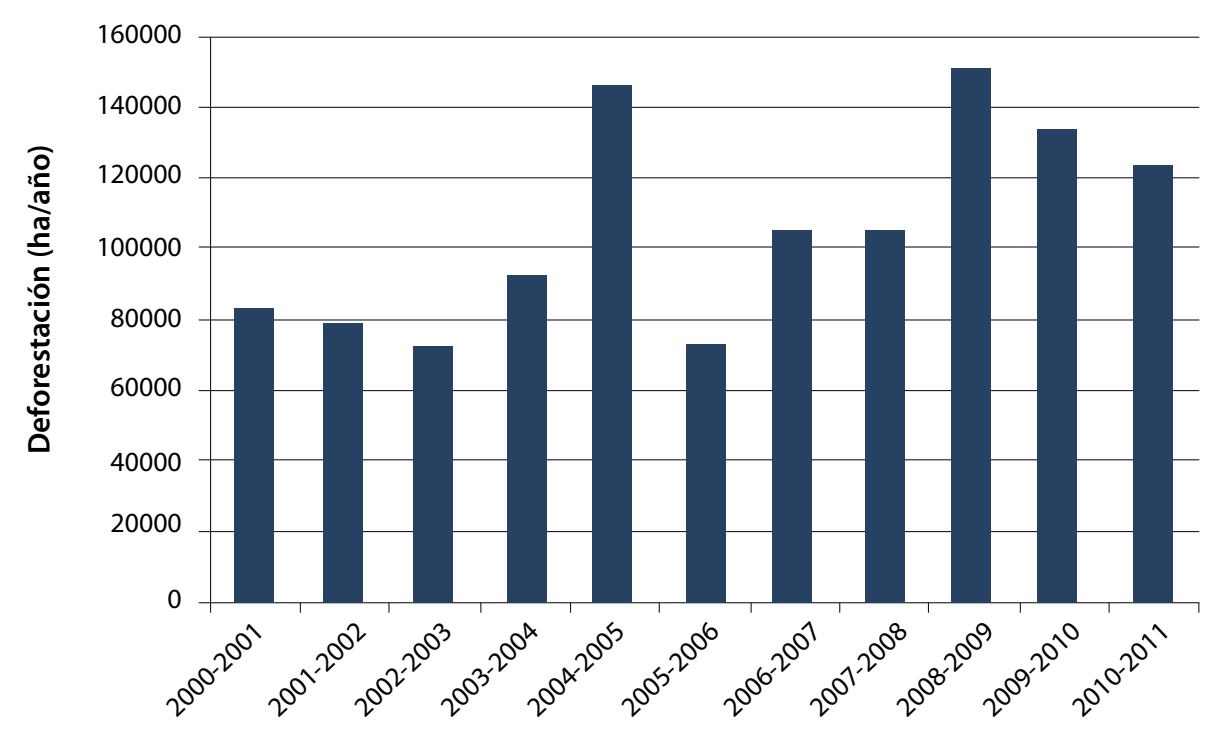

Figura 7. Evolución de la deforestación anual en la Amazonía peruana, periodo 2000-2011 (en hectáreas). Fuente: MINAM (2014d). 


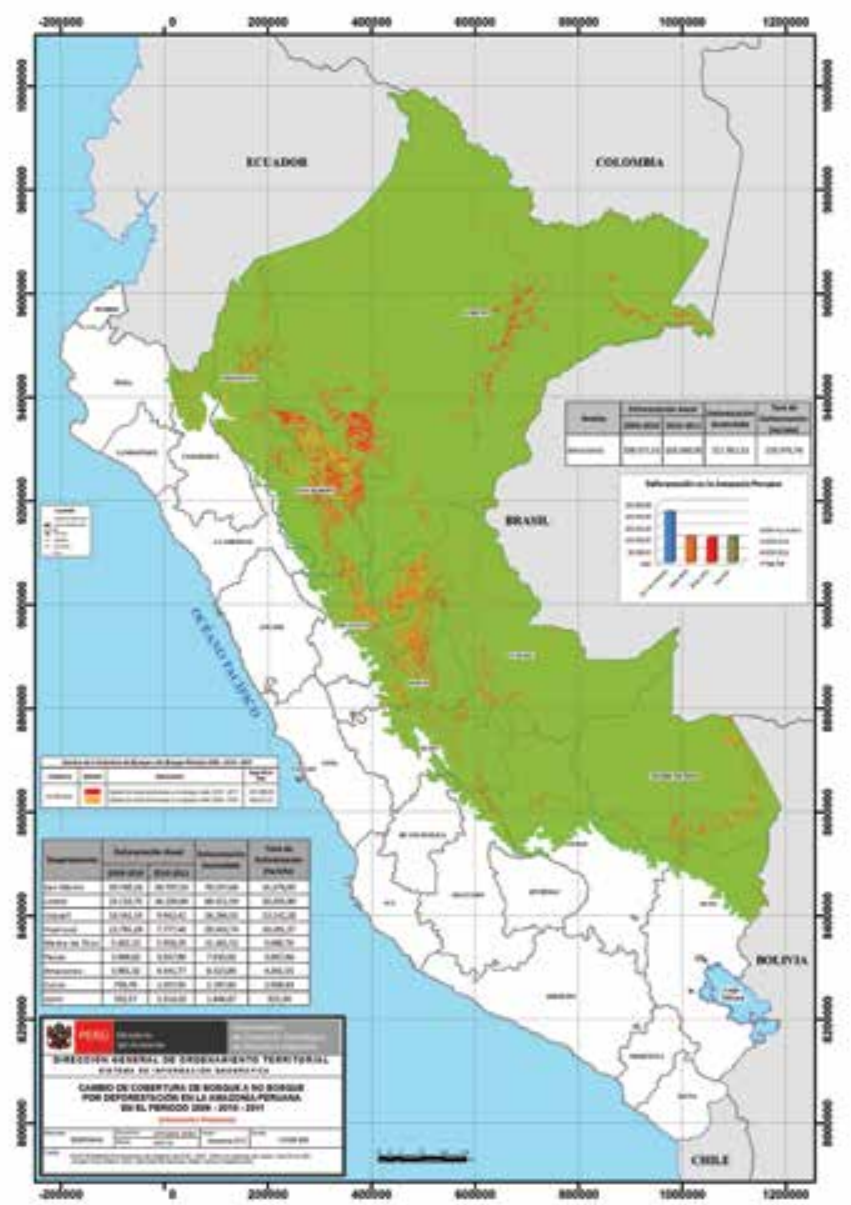

Figura 8. Deforestación en la Amazonía peruana 20092010-2011 (MINAM-DGOT 2013).

arboles de Hansen et al (2013), el Global Forest Watch del World Resources Institute disponibiliza datos del sistema de FORMA que detecta la perdida de cobertura forestal mediante imagnes de MODIS. Está disponible por: http://www. globalforestwatch.org.

Es importante observar que los diferentes mapas han utilizado definiciones diferentes y metodologías distintas algunos de los cuales no se encajan con la defición que el Proyecto REDD+ MINAM se utiliza. Aunque existan diferentes mapas (citados arriba), el Proyecto REDD+ MINAM ha optado por hacer sus propios estimaciones tanto de la deforestación cuanto del biomasa. Cabe destacar que algunos de los estimados sobre deforestación solo consideran la tala de bosques primarios y no la tala recurrente de bosques secundarios, lo que estaría subestimando los cálculos sobre emisiones de $\mathrm{CO}_{2}$ (Linares 2011). Además, las quemas no siempre afectan bosques primarios, sino en gran medida bosques secundarios que son talados de manera

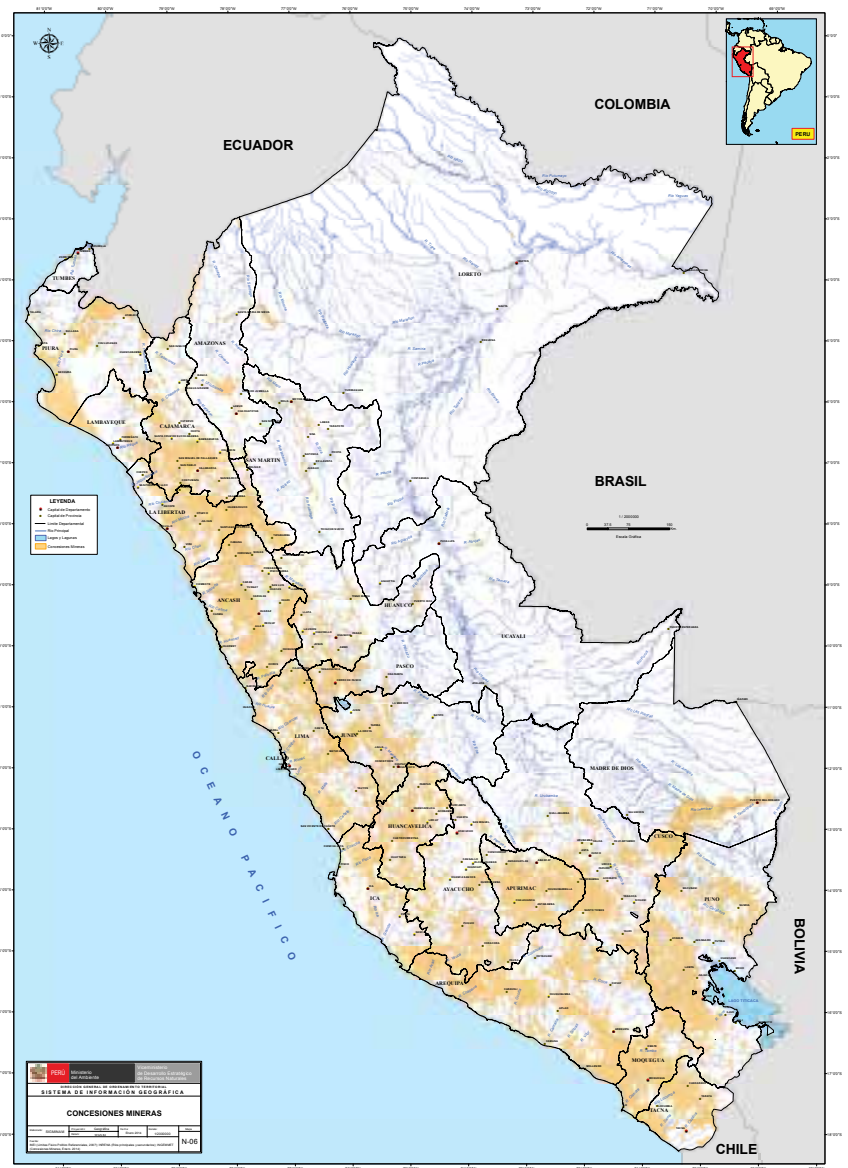

Figura 9. Mapa de concesiones mineras del Perú. Fuente: SIGMINAM (2014) .

a Disponible en: < http://geoservidor.minam.gob. pe/geoservidor/Archivos/Mapa/N06_CONCESIONES_ MINERAS.pdf $>$.

recurrente. Así pues, los datos de deforestación permitirían calcular solamente una fracción de las emisiones de $\mathrm{CO}_{2}$ realmente producidas. En tal sentido, Linares (2011) recomienda que el Inventario Nacional Forestal diseñe un procedimiento para cuantificar la superficie real de bosques primarios y secundarios que se talan y queman anualmente.

En lo que respecta a los promotores (drivers) de la deforestación y la degradación, existe una diferencia considerable entre regiones del país, y no se cuenta con una lista definitiva y cuantificada. Sin embargo, una cuantificación de ellos está dentro de las actividades del Proyecto REDD+ MINAM previstas para en el inicio de 2015. Hasta la fecha, algunos autores han buscado identificar y describir los principales agentes de la deforestación y la degradación, y las fuerzas que impulsan este proceso en las distintas regiones del Perú. 
Entre las causas directas de la deforestación recopiladas por Velarde et al. (2010), la agricultura migratoria es la de mayor importancia junto con las obras de infraestructura, como la construcción de carreteras, los proyectos hidroeléctricos y los proyectos de exploración y explotación de hidrocarburos. En el caso de la degradación de bosques en el Perú, las principales causas son la extracción (legal e ilegal) de madera, leña y productos forestales no maderables (PFNM), el pastoreo en áreas de bosques secundarios y purmas, y los incendios forestales. Según el estudio elaborado por CDI e INDUFOR para la preparación para el FIP, 75\% de la deforestación del periodo 2000-2009 ocurrió en parcelas de aproximadamente 0,5 hectáreas (CDI e INDUFOR 2012), lo que coincide con el tamaño de fincas de pequeños agricultores. Por su parte, Oliveira et al. (2007) indican que $75 \%$ de la deforestación del periodo 1999-2005 se realizó dentro del radio de 20 $\mathrm{km}$ de las carreteras.

\section{Inventarios Forestales Nacionales}

A nivel nacional y regional se han realizado y se vienen realizando algunos esfuerzos con el propósito de inventariar los bosques.

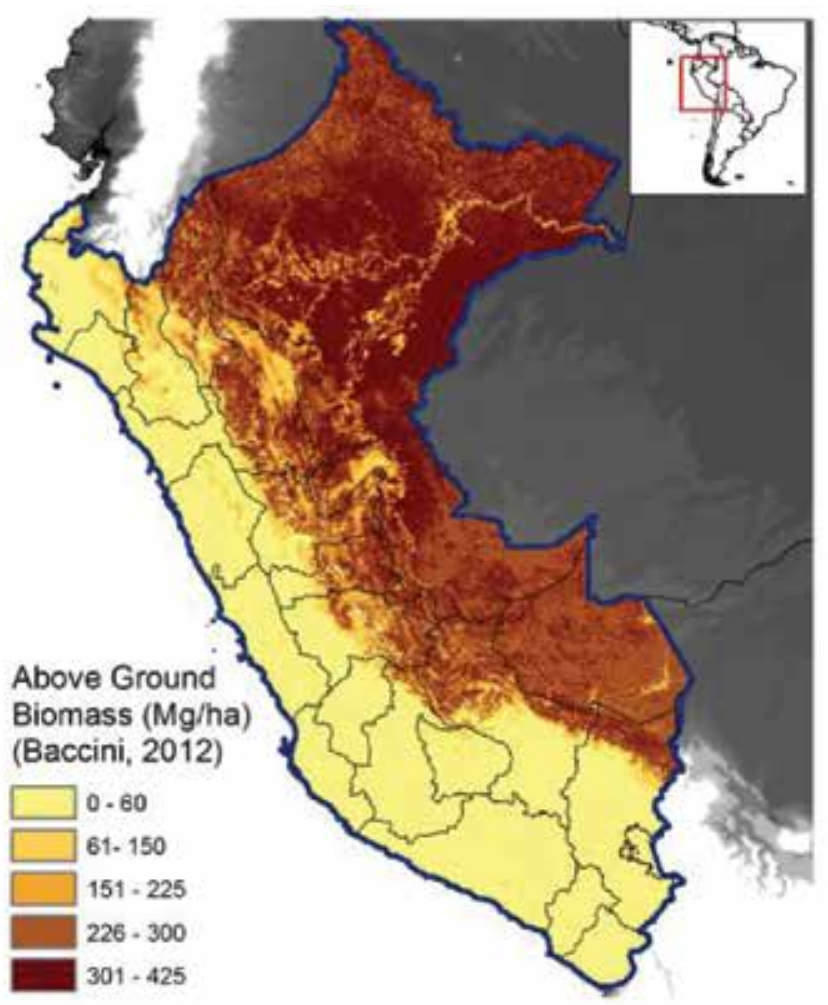

Figura 10. Mapa del contenido de biomasa sobre el suelo (Mg/ha) en el Perú por Baccini et al. (2012).

Fuente: Arief Wijaya, elaborado para esta publicación (2013).
En 1980, la Universidad Nacional Agraria La Molina (UNALM) recibió la solicitud de la Dirección General Forestal del MINAGRI de ejecutar el primer Inventario Forestal Nacional. De esta manera, se realizaron los inventarios de la provincia de Oxapampa (sobre 75.000 hectáreas de bosques de producción), de la microrregión Iberia-Ińapari (128.000 hectáreas) y de la micorregión ShiringayoyLoboyoc (590.000 hectáreas). En el departamento de Cusco se inició también un inventario de plantaciones forestales, pero fue luego discontinuado por agotamiento de los fondos.

El segundo y actual Inventario Forestal Nacional (iniciado en 2010) es un proyecto de iniciativa del Estado peruano que se realiza a través del MINAGRI, el MINAM, los Gobiernos regionales y otros actores nacionales, con el auspicio de FAO-Finlandia, en el marco del proyecto Inventario Nacional Forestal del programa "Sustainable Forest Management in a Changing Climate". El proyecto prevé la ejecución de tres fases: (i) institucionalización del proyecto, (ii) inventario forestal y (iii) difusión de resultados, en un periodo de cuatro años, que involucran un costo total de US\$ 5.168.021 con contribución del Gobierno

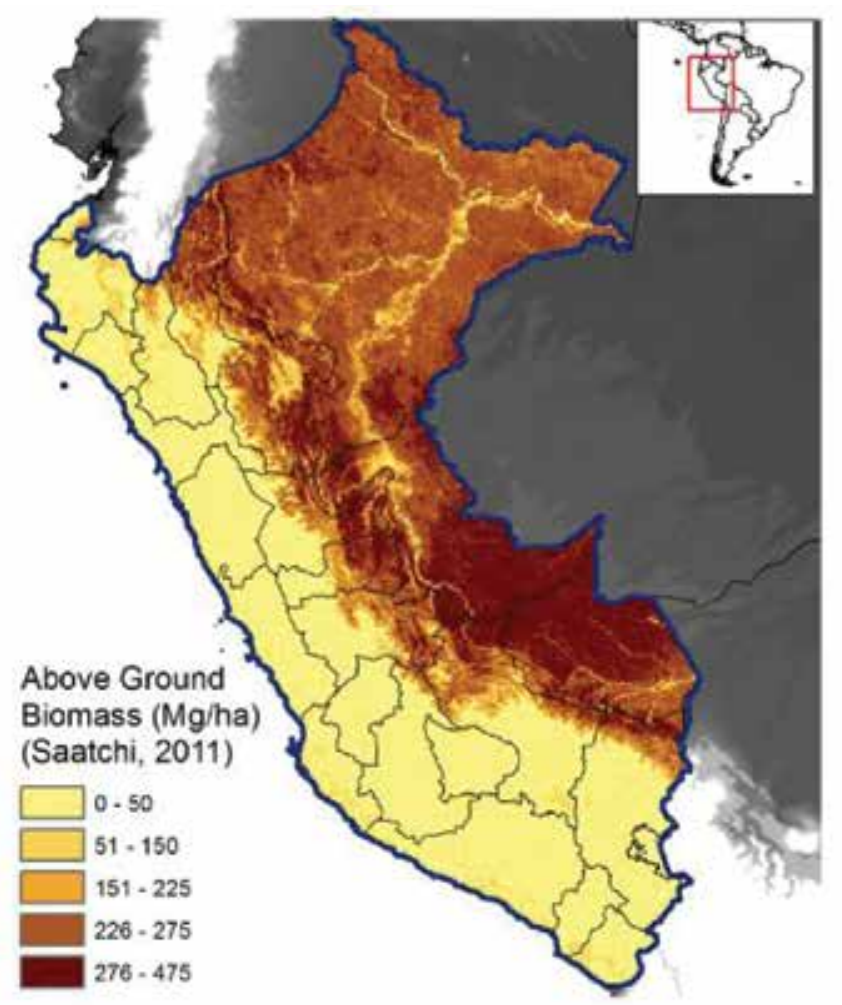

Figura 11. Mapa del contenido de biomasa sobre el suelo (Mg/ha) en el Perú por Saatchi et al. (2011). Fuente: Arief Wijaya, elaborado para esta publicación (2013). 
peruano y donantes. El inventario, además de evaluar el volumen de madera, tiene como propuesta estimar las reservas de carbono, la diversidad biológica y otros servicios ambientales como flora, fauna y belleza paisajística.

En la sistematización de información sobre los recursos forestales de Perú, Linares (2011) informa que el BANDIFF (Banco de Datos de Información Forestal, que elaboraba la Dirección General Forestal y de Fauna Silvestre [DGFFS]) cuenta con 27 inventarios de siete regiones (Amazonas, Cusco, Huánuco, Loreto, Madre de Dios, Pasco y Ucayali). De acuerdo con el autor, esta base de información proviene de los estudios de evaluación realizados en diferentes épocas por la Oficina Nacional de Evaluación de Recursos Naturales (ONERN).

Además de los inventarios forestales, el Perú cuenta con información de la recolección de datos para la Evaluación de los Recursos Forestales Mundiales (FRA). Las fuentes de datos para el informe de 2010 (FAO 2010) fueron recogidas de diversas instituciones, entre ellas las siguientes: el MINAGRI, el Instituto Nacional de Defensa Civil (INDECI), la Universidad Nacional Agraria La Molina, el Instituto Nacional de Recursos Naturales (INRENA) y la ONERN.

\section{Reserva de carbono en el uso o cobertura del suelo}

En el Perú, las mediciones de biomasa de la vegetación (natural o plantación) y del carbono del suelo fueron y vienen siendo realizadas con propósitos diferentes (p. ej.: investigación, mercado de carbono, etc.) y con protocolos de medición distintos. Las siete metodologías VCS (Verified Carbon Standard) aprobadas para proyectos de REDD+ proponen la medición de distintos tipos de depósitos de carbono.

En una reciente iniciativa, el Gobierno Regional de Madre de Dios y las instituciones que conforman la Mesa de Servicios Ambientales y REDD (MSAR) han establecido una base de datos de 608 parcelas de medición de biomasa. Esta iniciativa buscó proporcionar insumos para la elaboración de la línea base regional (MSAR-MdD 2014).

La gran variación en la estimación del carbono almacenado en los bosques se debe a las propias diferencias entre los diversos tipos de bosque, pero también al empleo de distintas metodologías y procedimientos de medición. Un ejemplo reciente de las implicaciones de estas diferencias puede constatarse en los resultados de los esfuerzos de distintos grupos de investigadores liderados por Baccini (Baccini et al. 2012) y Saatchi (Saatchi et al. 2011), que elaboraron mapas globales de biomasa sobre el suelo utilizando metodologías distintas (Figuras 10 y 11).

A nivel nacional, en el marco del Proyecto REDD+ MINAM, fue desarrollada la consultoría "Análisis y sistematización de la información de carbono forestal para el diseño e implementación de un sistema nacional MRV REDD+ en el Perú", que se elaboró herramientas para el cálculo de carbono en los bosques del Perú, con Nivel 2 de categoría/ especificidad (también conocido como Tier 2). De acuerdo a los resultados del estudio, el Proyecto REDD+ MINAM ha refinando estimaciones de biomasa para seis estratos de bosque que coinciden con el mapa de estratificación de tipos de bosques elaborado por el Inventario Nacional Forestal (INF): costa, sierra, selva alta de difícil acceso, selva alta accesible, selva baja, y zonas hidromórficas. Los resultados iniciales de estos cálculos fueron presentados en abril de 2014, y serán presentados en el marco de la COP20 por la publicación "Estimación de contenidos de carbono de la biomasa aérea en los bosques del Perú." De acuerdo con el enfoque escalonado (step-wise approach), que prevé mejorar la precisión de las estimaciones a lo largo del tiempo, se tiene la intención de refinar estos estratos con mayor cantidad de datos e información sobre la variabilidad de los bosques dentro de los estratos del INF.

Paralelamente, MINAM-DGOT elaboró un mapa junto con el Instituto Carnegie de la Geografía del carbono del Perú en alta resolución hecho con LIDAR (Asner et al 2014a, Figura 12). Según un estudio aún más recién con base en este mapa, Carnegie y MINAM-DGOT estimaron que 0,8 Pg de carbono están en bosques sub amenaza "inminente" de deforestación (Asner et al 2014b). Aunque los resultados del estudio de Carnegie con MINAM-DGOT son relevantes para las estimaciones de carbono y la elaboración de los niveles de referencia, hasta la fecha el Proyecto REDD+ MINAM no ha tendio acceso a los datos de estos estudios y no está utilizando estos resultados.

\section{Líneas de base y escenarios futuros de referencia}

El Perú ha optado por implementar REDD+ a través de un enfoque anidado (por niveles) también denominado "enfoque de canasta" (nested approach). Además, ha decidido establecer una escala subnacional por bioma (costa, sierra, selva) como unidad de análisis para los escenarios de referencia. 


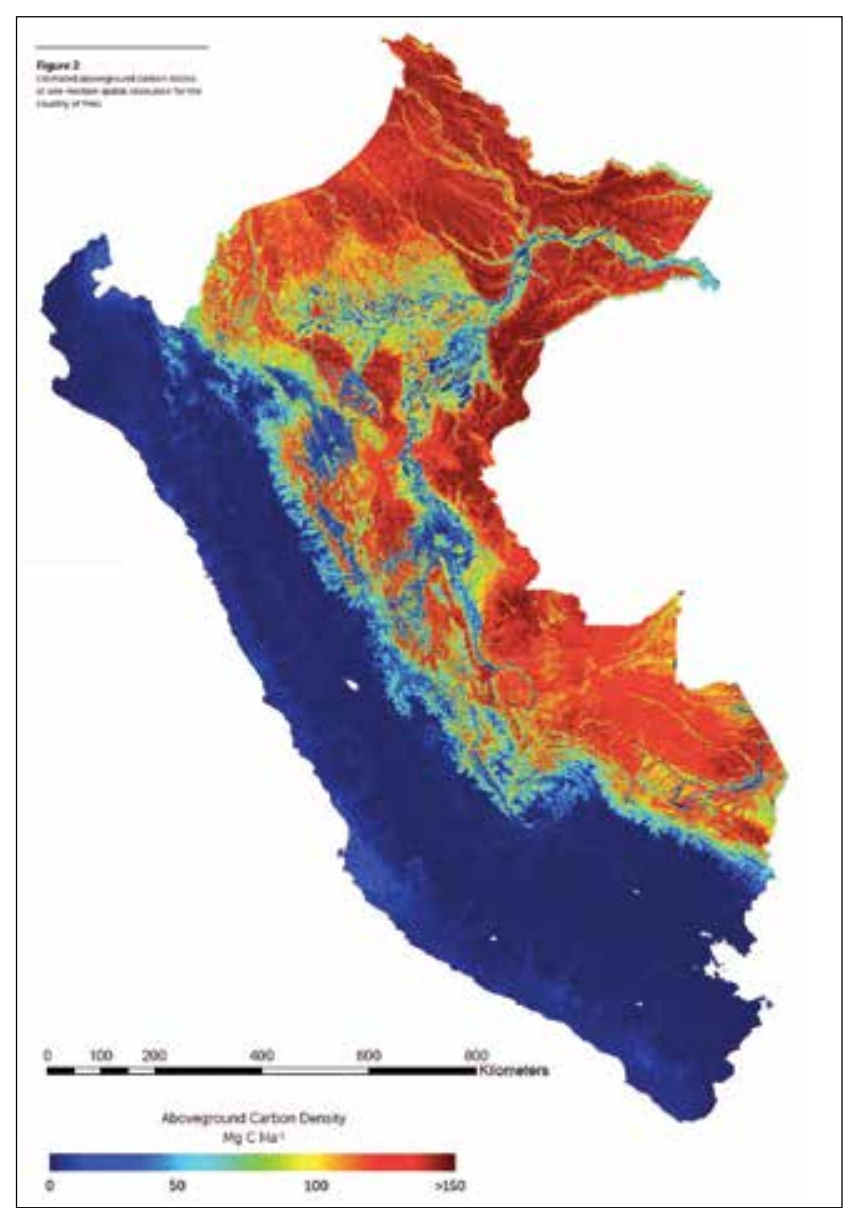

Figura 12. Geografía del carbono en Perú, Asner et al 2014a

Ello permite al país abordar la implementación a diferentes ritmos según se vayan desarrollando las capacidades técnicas para avanzar al nivel nacional. Al mismo tiempo, algunas regiones del país (San Martín, Madre de Dios y Cusco) ya cuentan con una primera aproximación de la información de línea de base, por medio de la elaboración de mapas de carbono preparados en el marco de las mesas de REDD+ regionales. Los escenarios de referencia departamentales de 2012 sufreron de superposición de áreas (Figura 13) y utilizaron metodologías diferentes. Con el objetivo de reconciliar estos problemas y tener niveles de referencia consistentes y nacionales, el Proyecto REDD+ MINAM viene desarrollando un nivel de referencia nacional (MINAM 2014d).

\section{Emisiones de GEl asociados al uso y cambio del uso del suelo}

El segundo Inventario Nacional de GEI, con año base 2000, identificó que las emisiones del Perú son menores que la media mundial, y que su contribución al flujo total de emisiones globales corrientes no llega al 1\%. Según el Inventario, el sector de USCUSS aportó la mayor proporción de emisiones de $\mathrm{CO}_{2}$ del país, con el $47 \%$. La principal fuente de emisiones fue la conversión de bosques a pasturas (deforestación), que aportó $110,060 \mathrm{Gg}$ de $\mathrm{CO}_{2}$, mientras que $53,541 \mathrm{Gg}$ de $\mathrm{CO}_{2}$ fueron removidos por cambios en la biomasa forestal o las reservas leñosas (Calvo 2008). Mediante el Proyecto de Planificación Ante el Cambio Climatico (PLANCC), se actualizó el inventario de GEI con datos de 2009. Resulta que el sector forestal representa 39\% de las emisiones con emisions de $112,6 \mathrm{Gg}$ de $\mathrm{CO} 2$ y remociones de $56,2 \mathrm{Gg}$ (PLANCC 2013).

Como forma de establecer un mecanismo oficial y permanente para contar con información actualizada y confiable sobre las emisiones de GEI en el país, se propuso (R. M. 092-2011-MINAM) el establecimiento de la Red de Generación de Datos para el Inventario de Gases de Efecto Invernadero (INFORMAGEI), que incluya de manera prioritaria el sector USCUSS, y una Plataforma Nacional de Monitoreo, Reporte y Verificación (MINAM

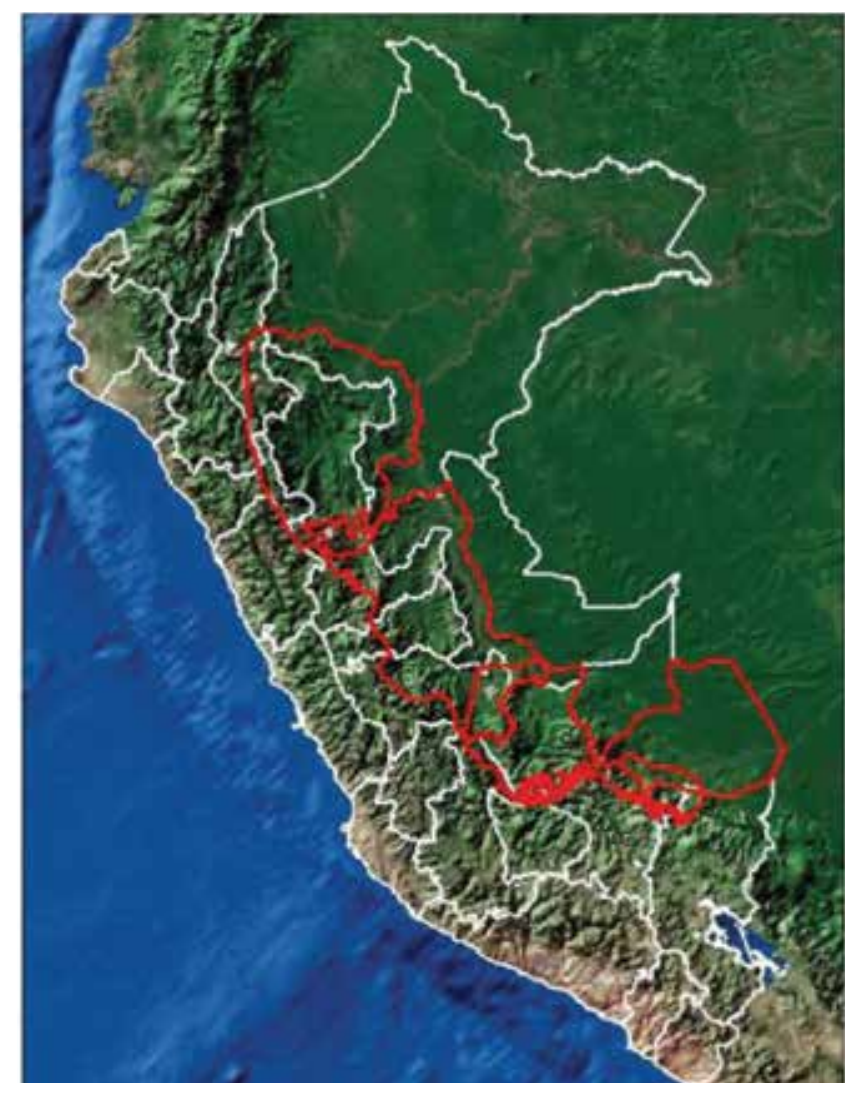

Figura 13. Áreas de escenarios de referencia en desarrollo en el Perú en 2012.

Fuente: Juan Felipe Villegas, elaborado en 2012 
2011b). La propuesta del MINAM es que la Red contribuya en la articulación de los actores que participan en la formulación de comunicaciones nacionales a la CMNUCC, en inventarios de GEI, en planes nacionales de desarrollo bajos en carbono y en programas de mitigación, con la finalidad de cuantificar las emisiones del país de manera más eficiente y efectiva.

\section{Proyectos e iniciativas que contribuyen al MRV de bosques y a la REDD+}

A febrero de 2011, Che Piu y García (2011) habían contabilizado los proyectos ejecutados en el Perú a través de la sociedad civil y el Estado. Según los autores, 35 proyectos eran ejecutados en 11 regiones, en diferentes fases de elaboración o implementación del documento de desarrollo del proyecto (PDD). De estos, 9 proyectos están siendo propuestos/ ejecutados en ANP de administración nacional y una regional; 13 en concesiones forestales maderables y no maderables (para ecoturismo y para conservación); y 15 en bosques de comunidades (13 en comunidades nativas y 2 en comunidades campesinas). En 2012, el MINAM compartió un mapa que incluye 41 proyectos, muchos de ellos sobrepuestos con los 35 de Che Piu y García. Al mismo tiempo, en un portafolio para el mercado de carbono, el Fondo Nacional del Ambiente registra 21 proyectos de REDD+ (FONAM 2012). Para el caso de Proyectos Forestales MDL, a pesar de que el FONAM indica 41 proyectos, apenas se encuentra 1 proyecto registrado en la CMNUCC. En las regiones de Madre de Dios, Ucayali y San Martín, se concentran actualmente la mayoría de las iniciativas subnacionales de REDD+. Es además donde se han generado mecanismos de coordinación entre los promotores de las diversas iniciativas de REDD+ y los respectivos Gobiernos regionales con el fin de generar bases comunes en temas como el análisis de las causas de la deforestación, líneas de base, monitoreo de la deforestación y medición de existencias de carbono (MINAM 2012b).

\section{Tecnologías, herramientas y sistemas de información disponibles para el MRV de REDD+ en el Perú}

En el Perú existen diversas fuentes de información, estadísticas y mapas relevantes a REDD+ y MRV, que aparecen listados a continuación. Sin embargo, se debe señalar que hay una falta de coordinación y coherencia entre estas fuentes. Por ejemplo, algunas informaciones se encuentran en distintas plataformas, mientras que otras difícilmente pueden ser ubicadas. En otros casos, hay desacuerdos e inconsistencias entre las informaciones reportadas por diferentes instituciones. La ausencia de una institución que centralice y analice estas informaciones y las metodologías utilizadas, y que promueva la comunicación y el intercambio de datos entre las diferentes instituciones del Gobierno, contribuye al escenario actual de inconsistencia.

\section{Base de información sobre recursos forestales}

Hasta 2013, la Dirección General Forestal y de Fauna Silvestre (DGFFS) del MINAGRI fue la entidad encargada de la gestión pública de los recursos forestales y de fauna silvestre dentro de sus competencias legales en el país. A partir de 2014, las funciones de la DGFFS fueron asumidas por el SERFOR, pero estas siguen siendo las mismas. La inauguración de SERFOR fue realizada en agosto 2014 y DGFFS y SERFOR están en proceso de fusión. La DGFFS/SERFOR cuenta con la Dirección de Información y Control Forestal (DICF) como sector responsable por producir los registros anuales resumidos sobre recursos forestales. Para el desarrollo de sus actividades, la DICF es abastecida con información forestal proveniente de los Gobiernos regionales (debido al proceso de descentralización) y de las "oficinas desconcentradas" de Administraciones Técnicas Forestales y de Fauna Silvestre (ATFFS). Actualmente existen 15 oficinas desconcentradas de las ATFFS, a cargo de administradores técnicos que, entre muchas otras funciones, tienen la responsabilidad de mantener informada a la DGFFS/ SERFOR sobre las actividades forestales en sus regiones. En los casos de las regiones que ya han pasado por el proceso de descentralización, han creado entes responsables por las mismas acciones de las ATFFS pero con nombres distintos en las regiones (e.g. Dirección Ejecutiva Forestal y de Fauna Silvestre de Ucayali, Dirección Regional Forestal y de Fauna Silvestre de Madre de Dios). La DGFFS/SERFOR (a través de las ATFFS y entes regionales) es responsable por los registros de concesiones forestales y de fauna silvestre.

Desde 1997, la DGFFS colocó a disposición de los usuarios la serie de anuarios Perú forestal en números, que presenta información cuantificada de las actividades de reforestación, extracción forestal, 
producción forestal maderable y no maderable (por productos, regiones y especies), e información sobre el comercio exterior de productos forestales diversos, procesada y sistematizada.

Otra fuente de información importante, el Programa de Desarrollo Productivo Agrario Rural (AGRORURAL) del MINAGRI, dispone información sobre la ubicación y extensión de las plantaciones. El Programa cuenta con 200 sedes y subsedes, ubicadas en 20 departamentos del Perú.

\section{Base de información sobre estadísticas y recursos agropecuarios}

La producción, el análisis y la validación de la información estadística nacional y regional sobre las variables agroeconómicas se encuentran bajo la responsabilidad de la Oficina de Estudios Económicos y Estadísticos (OEEE) del MINAGRI. La información es recopilada por las direcciones regionales de agricultura, a través de las cuales es posible acceder a los datos agropecuarios obtenidos mediante el Texto Único de Procedimientos Administrativos (TUPA).

La OEEE reporta anualmente información sobre los agentes económicos de las cadenas productivas agrícolas a través de su Anuario de la producción agricola. Los anuarios contienen información de variables como: superficie sembrada de principales cultivos transitorios, superficie cosechada, producción, rendimiento, y precios en chacra mensuales y anuales. Esta información es presentada a nivel nacional, regional y subregional. La elaboración de los anuarios está contemplada en el marco del Sistema Integrado de Estadística Agraria (SIEA).

Otras bases de información existentes que contribuyen a un mejor entendimiento de la situación de los recursos agropecuarios en el país son:

- Censos Nacionales Agropecuarios (CENAGRO). Estos no se realizan desde el año 1994.

- Sistema Integrado de Estadísticas Agrarias (SIEA, <http://siea.minag.gob.pe/siea/>), conformado por los órganos y organismos adscritos al MINAGRI, los Gobiernos regionales y locales, y sus diferentes dependencias en la materia.

- AGRORED Perú (<http://www.agroredperu. org/>), metasistema de información agraria diseñado para la gestión tecnológica, desarrollado por la Organización de las Naciones Unidas para la Alimentación y la Agricultura (FAO).

- Sistema Nacional de Información Forestal y de Fauna Silvestre (SNIFFS) ${ }^{9}$, de la DGFSS/ MINAGRI y parte $^{10}$ activa de AGRORED Perú.

- Sistema de Información de la Diversidad Biológica y Ambiental de la Amazonía Peruana (SIAMAZONÍA, <http://www.siamazonia. org $>$ ), creado por iniciativa del Proyecto Diversidad Biológica de la Amazonía Peruana (BIODAMAZ, Convenio Perú-Finlandia) ejecutado en el Perú por el Instituto de Investigaciones de la Amazonía Peruana (IIAP).

- Banco de Datos de Información Forestal (BANDIFF) desarrollado por la DGFSS/ MINAGRI en el marco del Proyecto FAOFinlandia (GCP/GLO/194/MUL). Se han incorporado buena parte de los inventarios realizados de 1991 a 2010.

- Centro de Documentación e Información Forestal (CEDINFOR, <http://cedinfor. lamolina.edu.pe $>$ ), desarrollado por la Cooperación Técnica Suiza (COTESU) y la Universidad Nacional Agraria La Molina (UNALM).

- Centro de Datos para la Conservación (CDCUNALM, <http://cdc.lamolina.edu.pe>) de la Facultad de Ciencias Forestales de la Universidad Nacional Agraria La Molina.

- Centro de Información Virtual (INFODOC 2012 $)^{11}$ de la Dirección General de Asuntos Ambientales Agrarios (DGAAA) del MINAGRI, que pone a disposición información agraria generada institucionalmente.

- Centro de Documentación (CENDOC, <http://www.agrorural.gob.pe/cendoc.html>), unidad de información y custodio oficial de la producción bibliográfica y documental del Programa de Desarrollo Productivo Agrario Rural (AGRORURAL).

- Base de datos CountrySTAT - FAOSTAT, de la FAO. (<http://www.fao.org/economic/ ess/countrystat/es/>), que ofrece estadísticas nacionales y subnacionales.

- Los compendios, informes y datos tanto sobre USCUSS, población entre otros, disponibles en

9 Disponible en: <http://dgffs.minag.gob.pe/index. php?option=com_content $\&$ view=article\&id=118\&Itemid $=63>$. 10 R. M. 0537-2006-AG.

11 Disponible en: <http://www.netvibes.com/ elizabethascencio\#SISTEMAS_DE_INFORMACION_ GEOGRAFICOS_DEL_PERU>. 
el sitio del Instituto Nacional de Estadistica e Informatica (INEI, http://www.inei.gob.pe)

\section{Base territorial}

Entre las principales fuentes de información y mapas relacionados con temas territoriales disponibles sin costo para los usuarios, están:

- GEOSERVIDOR (<http://geoservidor.minam. gob.pe>), desarrollado por el equipo del Sistema de Información Geográfica del Ministerio del Ambiente (SIGMINAM) de la Dirección General de Ordenamiento Territorial (DGOT)/ MINAM.

- GEOIDEP (<http://www.geoidep.gob.pe/>), Portal de la Infraestructura de Datos Espaciales del Perú, administrado por la Oficina Nacional de Gobierno Electrónico e Informática (ONGEI) de la Presidencia del Consejo de Ministros (PCM).

- Portal de Infraestructura de Datos Espaciales (<http://www.ccidep.gob.pe/poblados/ gestioncp.html>), del Comité Coordinador de la Infraestructura de Datos Espaciales del Perú (CCIDEP).

- GEOSERNANP (<http://geo.sernanp.gob.pe/ principal.php $>)^{12}$, del SERNANP.

- GEOPORTAL (<http://190.187.140.90/ign/>), del Instituto Geográfico Nacional (IGN).

- Catálogo de Metadatos del Instituto Geológico, Minero y Metalúrgico (INGEMMET) (http:// metadatos.ingemmet.gob.pe);

- GEOCATMIN Sistema Geológico Catastral Minero (<http://geocatmin.ingemmet.gob.pe/ geocatmin/index.html $>$ ) del INGEMMET.

- MTCGEO (<http://mtcgeo.mtc.gob.pe/ website/vial1/viewer.htm>), visor geográfico del Ministerio de Transporte y Comunicaciones (MTC).

- Sistema Nacional Integrado de Información Catastral Predial (<http://www.sncp.gob. pe:8087/ServicioSNCP/>) del Ministerio de Justicia y Derechos Humanos del Perú.

- Mapas Temáticos - DGFFS/MINAGRI, de la Dirección General Forestal y de Fauna Silvestre (DGFFS) del MINAGRI.

- Mapa Planimétrico del Perú (<http://dgaaa. minag.gob.pe/index.php/mapa-planimetrico >), de la Dirección General de Asuntos Ambientales Agrarios (DGAAA) del MINAGRI.

12 También disponible en: <http://geo.sernanp.gob.pe/ geoservidor/index.php>.
- Visualizador de Mapas del Sistema de Información sobre Comunidades Nativas de la Amazonía (SICNA) (<http://190.41.250.97:82/ pmapperibc/map.phtml>), desarrollado por el Instituto del Bien Común (IBC).

- Información espacial del Ministerio de Educación (MED) (<http://escale.minedu.gob. pe/descargas/mapa.aspx $>$ ), de la Unidad de Estadística Educativa (ESCALE) del Ministerio de Educación (MINEDU).

- Sistema de Información Cartográfica de Perú (<http://www.geog.umd.edu/landcover/globalcover.html $>$ ), de la FAO.

- Mapa de Elevación Digital a partir de DEM para el Perú. Puede ser obtenido en el sitio web del GTOPO30 y del GEOPORTAL CGIARCSI (<http://edc.usgs.gov/products/elevation/ gtopo30/gtopo30.html>).

- El mapa de cobertura del suelo para el Perú puede ser desarrollado a partir de bases de datos globales obtenidas de GlobCover 2005/2008 (v2)/2009 o JRC Trees, 2002 (<http://geoserver. isciences.com:8080/geonetwork/srv/en/ metadata.show?id=228\&currTab=simple y http://geonetwork4.fao.org/geonetwork/srv/en/ fra.home >).

\section{Mapas temáticos regionales}

- Plataforma Map@mazonico (<http://biocan. comunidadandina.org/mapamazonico/ $>$ ), desarrollada en el marco del Programa BioCAN.

- Servidor de mapas del IIAP (<http://www.iiap. org.pe/MapasAmbientales.asp $>$ ) .

- Herramienta de investigación MAPAZ (<http:// gismap.ciat.cgiar.org/mapaz/>), un visor desarrollado por el Consorcio Internacional Iniciativa Amazónica (IA).

- Red Amazónica de Información Socioambiental Georeferenciada (RAISG) (http://raisg. socioambiental.org), mapas de áreas protegidas, tierras indígenas e otras informaciones socioambientales

- Servidor de mapas del Gobierno Regional de Loreto (<http://www.regionloreto.gob.pe/ OATSIG/cartografia_regional.htm>).

- Servidor ${ }^{13}$ de mapas del Gobierno Regional de Ucayali.

13 Disponible en: <http://www.regionucayali.gob.pe/grpp/ index.php?option=com_content\&task=view\&id=146\&Item id $=56>$. 


\section{Pasos firmes en camino hacia un sistema de MRV de USCUSS y REDD+}

A través del Proyecto REDD+ MINAM, desde el año 2011 el MINAM viene trabajando en: (i) el análisis del marco legal y la institucionalidad relacionados con el sistema de MRV; (ii) la identificación de vacíos de información y capacidades; (iii) el diseño y propuesta de marcos metodológicos estandarizados (MME); (iv) una propuesta de diseño e implementación del Sistema de Registro Nacional de Proyectos REDD+.

Otras iniciativas contempladas o relacionadas con PLANAA-Perú: 2011-2021 y que vienen contribuyendo al desarrollo de un sistema de MRV de REDD+ nacional son:

- "Plan de fortalecimiento de capacidades técnicas para la implementación de un sistema nacional MRV para REDD+ en el Perú", desarrollado por Conservación Internacional Perú y Éco Ressources Carbono para el FONAM y el MINAM. Sirvió de base para el desarrollo de módulos del curso de capacitación "Inventario de Gases de Efecto Invernadero" realizados entre fines del 2012 y abril 2014 con gobiernos regionales y la sociedad civil.

- Proyecto de Inventario Nacional Forestal (INF) ${ }^{14}$, una iniciativa del MINAGRI, el MINAM, GOREs (Gobiernos Regionales), con el auspicio de FAO-Finlandia:

- Diseño e implementación de un Sistema de Información Georeferenciada para el Monitoreo de la Dinámica de Cambios de Uso de la Tierra, de iniciativa de la DGOT/MINAM.

- Plan de Inversión Forestal (FIP) para el Perú (aprobado el 30 de octubre de 2013), que cuenta con cuatro propuestas de intervención (tres de ámbito regional y una de nivel nacional). Entre otras sinergias, el FIP debe contribuir US\$ 3 millones al diseño e implementación del sistema nacional de monitoreo propuesto en la RPP de 2013.

- Plan Nacional de Monitoreo de la Cobertura Forestal en el marco del proyecto "Monitoreo de la deforestación, aprovechamiento forestal y cambios de uso del suelo en el bosque panamazónico", realizado por el MINAM y el

14 Disponible en: <http://geoservidor.minam.gob.pe/ifn/ datosproyecto.aspx>.
MINAGRI, en coordinación con la Organización del Tratado de Cooperación Amazónica (OTCA).

- Proyecto Iniciativa Hatoyama (Japón), iniciativa del MINAGRI con auspicio del Gobierno de Japón, que incluye la donación de imágenes satelitales, equipos y software destinados a monitorear y conservar los bosques de todo el territorio peruano.

- Plataformas y sistemas de información agroambientales existentes en el país (p. ej.: GEOSERVIDOR $^{15}$ del MINAM).

\section{Propuesta de Sistema de Registro de Proyectos REDD+ Perú}

De conformidad con el artículo 36 del Reglamento de Organización y Funciones (ROF) del MINAM, es función de la Dirección General de Cambio Climático, Desertificación y Recursos Hídricos (DGCCDRH) del MINAM mantener un Registro Nacional de Proyectos de Adaptación y Mitigación, así como de las investigaciones y estudios sobre el cambio climático y aquellos elaborados en el marco de la Convención del Clima.

El MINAM suministrará información que permita efectuar la contabilidad de las emisiones derivadas del carbono forestal enmarcadas por este mecanismo. Se busca "fomentar la transparencia en la información y contribuir en salvaguardar los derechos de los usuarios del bosque y de las tierras donde estas iniciativas o proyectos se realicen".

De acuerdo con la propuesta (remitida por el MINAM al Grupo REDD Perú el 24 de agosto de 2012), se está avanzando en el diseño del registro de iniciativas de REDD+ la cual tendrá carácter obligatorio para el diseño o implementación de estas iniciativas/proyectos. En este sentido, corresponderá al MINAM verificar, evaluar y realizar una supervisión periódica (anual) de la información proporcionada (registrada) por los ejecutores. Cabe destacar que la información brindada al registro tiene carácter de declaración jurada, y que únicamente se considerará como proyectos REDD+ a aquellos que logren su inscripción en el registro de acuerdo a los requisitos y procedimientos a establecerse en la reglamentación de la Ley de Retribución por Servicios Ecosistémicos.

15 Disponible en: <http://geoservidor.minam.gob.pe/ geoservidor/maps.aspx>. 
En julio de 2014, MINAM inauguró la Plataforma Nacional de Información sobre los Mecanismos de Retribución por Servicios Ecosistémicos (http:// minam.ciat.cgiar.org) que contiene una sección para REDD+. Dicha Plataforma sirve como Fase 1 del Registro REDD+. En esta fase la Información inscrita en la Plataforma no cuenta con ningún aval por parte del estado. Dicha Plataforma estará disponible en el link: http://serviciosecosistemicos. minam.gob.pe/ desde su lanzamiento en la COP20). Hasta el inicio de noviembre de 2014, la Plataforma compiló información de 10 iniciativas REDD+ con información sobre, entre otras: los proponentes de las iniciativas, sus actividades y el estado de ejecución del proyecto (diseño, transacción de bonos, etc).

A la fecha, los areglos institucionales para MRV aún están en construcción. Para maximizar la consistencia del sistema y viabilizar la coordincación intersectorial, el sistema de MRV nacional debería estar conectado a los otros sistemas ambientales del país, como es el caso de: (i) el Sistema Nacional de Gestión Ambiental (SNGA), conformado por el Sistema Nacional de Información Ambiental (SINIA) y los Sistemas de Información Ambiental Regionales (SIAR) y Locales (SIAL); (ii) la Red de Generación de Datos para el Inventario de Gases de Efecto Invernadero (INFORMAGEI), que tomará en cuenta de manera prioritaria al sector USCUSS, a su vez relacionado con el Inventario Nacional de GEI (INGEI); y (iii) el Sistema Nacional de Monitoreo Forestal. Estos sistemas podrían contribuir a vincular la información utilizada en el sistema de MRV entre los Gobiernos regionales, el Gobierno nacional e instituciones que tienen la responsabilidad de regular la propiedad de la tierra y la gestión de los recursos y servicios ambientales en el Perú (p. ej.: la Intendencia de Flora y Fauna Silvestre del MINAGRI, OSINFOR, las direcciones regionales de agricultura (DRA) e INGEMMET, etc.).

\section{Contabilidad de reducción de emisiones de GEl subnacional y nacional: enfoque anidado}

Además de contabilizar las reducciones de emisiones derivadas de los proyectos y programas REDD+ (que serán registradas en la plataforma nacional), es también necesario contabilizar y verificar la reducción de las emisiones subnacionales (derivadas de las distintas regiones), así como del país.

A nivel regional, la propuesta contemplada en la RPP de 2013 determina que las proyecciones (escenarios de referencia) que se realicen a nivel regional serán desarrolladas siguiendo las modalidades y procedimientos propuestos por el nivel nacional y actualizadas por lo menos cada 10 años. En este sentido, el MINAM acompañó indirectamente el desarrollo de las iniciativas San Martín y Madre de Dios, buscando que estas sirvan como base para otras regiones y para construir la línea de base nacional de carbono. A la fecha, el Proyecto REDD+ MINAM se cuenta con avances para la construcción de los escenarios para el bioma amazónico.

A nivel nacional, en 2013 el MINAM ha desarrollado herramientas para el cálculo de carbono para los bosques del Perú, obteniendo mapas de carbono con Nivel 2 de categoría/especificidad (Tier 2). De acuerdo con la información presentada en la reunión el GT-REDD de la Comisión Nacional de Cambio Climático (el día 17 de diciembre de 2012) ${ }^{16}$, el trabajo buscó asegurar la compatibilidad de los resultados obtenidos (mapas de carbono) con el marco metodológico anidado del VCS. En 2014, han presentado los avances en diferentes reuniones y otros serán presentados en el marco de la COP20.

\section{Precondiciones para el establecimiento y la manutención de un sistema de MRV de USSCUSS y REDD+ nacional y regional}

Sobre la base del análisis del registro histórico de los debates internacionales sobre el tema y de la revisión de las plataformas tecnológicas, los sistemas de información, las capacidades existentes y el marco legal del país, son expuestas algunas de las precondiciones necesarias para el diseño, el establecimiento y la manutención de sistemas de MRV regionales y nacional. Para facilitar la comprensión, las precondiciones están agrupadas en aspectos: (i) metodológicas/ tecnológicas, (ii) de transparencia / institucionales, (iii) económicas y (iv) sociales/culturales.

\section{Precondiciones metodológicas/ tecnológicas}

\section{Referidas a la teledetección y el monitoreo}

a. Definir/estandarizar el sistema y método de monitoreo de la cobertura de los bosques, cambio de uso de suelo y de la superficie deforestada.

16 Disponible en: <http://www.gruporeddperu.net/index. php?limitstart $=10>$. 
El MINAM viene utilizando dos sistemas/ metodologías de monitoreo del bosque y de la deforestación, con objetivos diferentes: (i) el software CLASlite, adoptado por la DGOT como parte del convenio entre el MINAM y el Instituto Carnegie de la Universidad de Stanford; (ii) la metodología desarrollada de la Universidad de Maryland, utilizada por el equipo del Proyecto REDD del Programa Nacional de Conservación de Bosques (PNCB) en colaboración con el MINAGRI. A pesar de que ya han iniciado los esfuerzos para buscar formas de fusionar las dos metodologías, ambas presentan limitaciones, principalmente en cuanto a la alta dependencia de los generadores (universidades) de los sistemas, y no contabilizan adecuadamente el proceso de degradación y de recuperación de los bosques.

b. Definir/estandarizar el software utilizado para SIG y teledetección en entidades publicas. Un conjunto de programas y herramientas para el SIG (Sistemas de Información Georeferenciada) y teledetección están disponibles de forma gratuita (open source / freeware) a los usuarios de entidades públicas o privadas.

Entre los programas de teledetección más utilizados en el Perú (y América Latina) están Erdas Imagen, ERMapper y ENVI. En un análisis comparativo ${ }^{17}$ de costo-beneficio, el software de procesamiento de imágenes de satélite que mejor se adecúa a las necesidades de la DGFFS del MINAGRI fue el módulo Erdas lmagine Objective. Por otro lado, el Proyecto REDD+ MINAM utiliza ENVI y ArcGIS. La utilización de los mismos programas (o programas compatibles) permitiría el uso mas eficiente de los recursos y el intercambio de información, facilitando también los procesos de formación/capacitación.

c. Medir y monitorear no solo los procesos sino también a los promotores (drivers) de la deforestación y degradación forestal.

Como se ha discutido líneas arriba, aunque existen datos sobre los drivers de la deforestación a nivel local y regional, no hay datos concretos a nivel nacional. El análisis de agentes y causas (directas y subyacentes) de la deforestación y la degradación debe identificar y relacionar los estratos socioeconómicos con dinámicas de deforestación en las distintas áreas dentro de la región de referencia. Algunas metodologías VCS (VM0006/0007/0009 e 0015) disponen de recomendaciones y procedimientos para la

17 Realizado en enero de 2012. Para más información, ver el Informe Técnico Previo 004-2012-AG-OA-UTI. identificación y el análisis de agentes y causas de la deforestación. El Proyecto REDD+ MINAM iniciará la cuantificación de los drivers enel primer semestre de 2015.

d. Gestionar y formalizar alianzas entre instituciones responsables por la teledetección y monitoreo de agencias espaciales internacionales.

El Proyecto REDD+ MINAM ha propuesto la formación de una institución interministerial para la teledetección y el monitoreo como un mecanismo para facilitar la consolidación de informaciones dispersas y coherencia entre los datos utilizados por diferentes entidades. Cabe a los ministros y la PCM tomar una decisión. Mientras que hay retos institucionales para establecer este tipo de entidad, su constitución se ve de suprema importancia para MRV y otras iniciativas de planeamiento y ordenamiento del territorio nacional.

e. Determinar variables mínimas y procedimientos

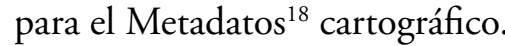

El SIGMINAM ha implementado su catálogo Metadatos con el software libre (open source)

GeoNetwork, que tiene la capacidad de buscar mapas y documentos a través de un catálogo estructurado.

La agencia del Federal Geographic Data Comittee (FGDC) pone a disposición de los usuarios herramientas de metadatos cartográficos.

f. Definir el enfoque de clasificación de "uso" o "cobertura" del suelo

Como se hizo en Ecuador y México, los trabajos elaborados por el Proyecto REDD+ MINAM utilizan las clases de uso y cobertura del suelo definidas por el Grupo Intergubernamental de Expertos sobre el Cambio Climático (IPCC), referentes al Nivel I de jerarquía. Para la determinación de los demás niveles (II, III y IV), se recomienda utilizar uno de los dos principales sistemas de clasificación empleados: (i) el sistema CORINE Land Cover (utilizado por Colombia), desarrollado y promovido por la Comisión Europea y las Naciones Unidas; y (ii) el sistema de clasificación de cobertura del suelo de $\mathrm{FAO} /$ PNUMA, Land Cover Sistema de Clasificación (LCCS), que está en fase de aprobación para convertirse en un estándar ISO.

g. Determinar un sistema de clasificación de cobertura del suelo regional lo más especifico posible.

18 El Metadatos cartográfico es un archivo que describe las características básicas de recursos de información de los datos espaciales y las metodologías utilizadas. 
Teniendo en cuenta la heterogeneidad geográfica del país, es necesario que el análisis nacional incluya una variable regional o se desarrollen análisis regionales independientes.

\section{Referidas a la medición y el monitoreo de carbono}

a. Establecer la Red Nacional de Inventarios de GEI.

Entre las metas trazadas en el Plan de Acción de Adaptación y Mitigación frente al Cambio Climático destaca el "Establecimiento de la Red Nacional de Inventarios de GEI (INFORMAGEI)". Se recomienda determinar la frecuencia de mediciones sobre la base del objetivo y tipo de proyecto, el tipo de componente muestreado, el tipo de manejo, la velocidad y magnitud del cambio en las reservas de carbono, y la exigencia del comprador de crédito.

b. Fijar niveles de categorías para la estimación de emisiones y remociones de GEI en función de los recursos financieros y humanos disponibles. Para Wertz-Kanounnikoff et al. (2008), dependiendo de la disponibilidad de datos y la magnitud de los cambios esperados en el reservorio, una opción es combinar los Niveles (Tiers). Vallejo y Rodríguez-Noriega (2008) recomiendan usar los niveles más altos posibles para los reservorios de carbono más importantes. Actualmente, el Perú se utiliza los factores de emisión por defecto del IPCC, pero se están desarrollando factores nacionales como parte del Proyecto REDD+ MINAM, con la intención de seguir un enfoque escalonado (step-wise approach) para ir perfeccionando las estimaciones de acuerdo con la disponibilidad de datos e información. Mientras que hay datos disponibles sobre la biomasa aérea, para la cuantificación del carbono en el suelo se necesita investigaciones de campo, en especial en las zonas hidromórficas, muchas de la cuales tienen suelos turbosos con niveles altos de carbono.

c. Establecer una proyección nacional de los cambios de uso y cobertura del suelo y niveles de referencia de emisiones de GEI que contemplen las proyecciones establecidas en las regiones del país.

Aún no existe un consenso internacional acerca de cómo establecer los niveles de referencia. La proyección de los cambios de uso y cobertura del suelo debe considerar las variables (potencialmente) relacionadas con las causas directas y subyacentes de la deforestación y degradación, como: (i) factores demográficos; (ii) factores económicos; (iii) usos del suelo que podrían darse a futuro (p. ej.: expansión agrícola y pecuaria); (iv) plan de inversión en infraestructura (MEF). Actualmente, el Proyecto REDD+ MINAM se encuentra desarrollando estos escenarios nacionales.

d. Definir un enfoque de percepción remota para monitorear la degradación forestal.

Aunque el Perú ha avanzado con la estimación de las tasas de deforestación, falta información sobre la degradación. Tomando en consideración la importancia de la explotación de madera, de los incendios forestales y de la extracción de leńa como emisores de GEI, se requiere un sistema para monitorear la degradación. El mapa de carbono desarrollado por Carnegie y MINAMDGOT (Asner et al 2014b) tiene información sobre las áreas degradadas que podrían ser incluidos en los análises del Proyecto REDD+ MINAM.

e. Elaborar una base de mapas multitemporales de los usos del suelo.

El sistema de MRV debe contar con mapas multitemporales de los usos del suelo que permitan evaluar la dinámica (pasado y presente) de la cobertura forestal y la tendencia de cambio (escenarios de referencia). Para monitorear actividades e iniciativas de REDD+ es necesario contar con mapas del área de referencia que ilustren la situación (cobertura o uso del suelo) antes y después del inicio de la actividad del programa/proyecto. Mayoritariamente, los mapas actuales no diferencian entre los distintos usos del suelo y no consideran la diferencia entre bosques primarios y purmas y otros bosques secundarios.

f. Contemplar el rastreo de las fugas de los proyectos/programas/iniciativas.

Debido al uso de un enfoque anidado, el área de imagen de cobertura utilizada para la interpretación debe ser no solo para los límites del área de la región política, sino también para toda el área donde se contempla cualquier tipo de fuga directa. Se debe resolver la superposición de áreas de referencia de los escenarios regionales para la consolidación nacional.

g. Seleccionar y validar modelos alométricos para la estimación de la biomasa de acuerdo con cada región/bioma del país.

Es recomendable emplear ecuaciones alométricas específicas para cada región/bioma/ecosistema. De no ser posible, es necesario seleccionar y validar (utilizando datos de campo) los modelos alométricos disponibles en la literatura. Hasta 
el momento, los proyectos en el Perú han utilizado las ecuaciones generales para bosques tropicales elaboradas por Chave et al (2005). Aunque hay nuevas ecuaciones relevantes para el Perú (Feldspauch et al. 2012, Chave et al. 2014), no se están utilizando ecuaciones generalizadas provenientes de los bosques peruanos.

h. Determinar factores de emisión por defecto para cada región/bioma del país.

Las directrices ${ }^{19}$ del IPCC para los inventarios nacionales de GEI contienen factores de emisión y métodos de cálculo de emisiones para todos los sectores definidos en la CMNUCC. Sin embargo, debido a la alta heterogeneidad de los biomas peruanos, es recomendable establecer convenios con universidades para que desarrollen investigaciones acerca de los factores de emisión adecuados para el clima y la vegetación de las distintas regiones del país.

\section{Precondiciones de transparencia, institucionalidad y gobernanza}

\section{Conceptuales}

a. Todos los conceptos relacionados con el sistema de MRV deben estar establecidos y consensuados, y ser accesibles.

La forma y los límites del MRV de los cambios de uso del suelo son afectados según cómo los conceptos relacionados con estos temas están definidos y si los parámetros que determinan sus umbrales están claramente establecidos o no. Aunque existen definiciones de "bosque" disponibles (p. ej: de la FAO y otros), los cálculos actuales de tasas de deforestación se realizan mediante teledetección, a través de una interpretación de la probabilidad de bosque / no bosque del área en consideración, y no corresponden directamente a estas definiciones. Las propuestas de definiciones debe considerar la diversidad existente entres las regiones del país, los conceptos no deben dar margen a la doble interpretación y las clasificaciones no deben ser contradictorias. Los sistemas de MRV deben contar con vocabularios disponibles en la plataforma en línea.

19 Disponible en: <http://www.ipcc-nggip.iges.or.jp/public/ $\mathrm{gl} /$ spanish.html>.

\section{Referidas a la publicación de la información}

a. Divulgar reportes de USCUSS, REDD+ y GEI con la mayor frecuencia posible.

Para UN-REDD (2009), en el caso de un sistema de MRV que responda a los compromisos de NAMA, esté vinculado a las comunicaciones nacionales de GEI y/o en caso de REDD+ se convierta en un mecanismo financiero internacional, probablemente la frecuencia de los informes será anual, como en todos los demás mecanismos financieros de la CNMNUCC. Sin embargo, los sistemas de monitoreo forestal internacionales actuales presentan informes cada 5 años (p. ej.: FAO/FRA). El Proyecto REDD+ MINAM estima una frecuencia de 5 ańos.

b. Establecer sistemas de alerta temprana. Se recomienda la elaboración de informes resumidos de la situación nacional/regional con el menor periodo posible. En áreas deforestadas (corte total), un sistema de monitoreo con alerta temprana puede contribuir a las acciones de fiscalización y cumplimiento, llevando a la acción a las instituciones responsables de la fiscalización. En áreas de degradación ilegal, además del establecimiento de responsabilidades, las instituciones de fiscalización pueden actuar para detener y revertir el proceso. El sistema FORMA, que alerta sobre la pérdida de cobertura, alcanza los bosques peruanos, y el sistema de monitoreo de focos de calor del Instituto Nacional de Pesquisas Espaciales (INPE-Brasil) cubre la Amazonía peruana. El sistem de Terra-i también está activo en el Perú.

\section{Referidas a la accesibilidad y verificación de la información}

a. El portal web oficial debe estar disponible para los interesados.

Entre otras informaciones, el portal debe contener: (i) los reportes de los resultados del MRV; (ii) imágenes y datos utilizados en la teledetección de uso y cambios de uso del suelo; (iii) la plataforma de registro de iniciativas de REDD+, accesibles a toda la sociedad (y potenciales financiadores), buscando evitar la superposición de financiamientos en la misma área para los mismos servicios ambientales/ecosistémicos.

b. Incorporar directrices nacionales transparentes para el MRV.

Las directrices constituyen un conjunto de instrucciones que dirigen los procedimientos en cuanto a organización, articulación o desarrollo del sistema de MRV. Estas deben contemplar 
una estructura detallada relacionada con: la gobernanza necesaria para la implementación, las formas de financiamiento, la participación, las salvaguardas socioambientales y la gestión de la información, entre otras acciones.

c. Seguir los principios y recomendaciones del IPCC.

Todas las actividades de MRV y estimaciones de GEI deben seguir los cinco principios de informes del IPCC y ser: transparentes, comparables, consistentes, precisas y completas, tanto como sea posible, reduciendo la incertidumbre, en cuanto a las capacidades nacionales y las capacidades de los permisos. $\mathrm{La}$ información y los datos resultantes deben ser coherentes, fiables y reproducibles.

\section{Referidos a la institucionalidad y gobernanza}

a. Establecer los roles y funciones de la entidad/ agencia ejecutora del sistema de MRV.

Entre las responsabilidades y funciones que deben estar a cargo de la entidad/agencia ejecutora se encuentran: (i) definir metas y estrategias integradas e integradoras de implementación del sistema; (ii) proponer y orientar el desarrollo de herramientas y metodologías de medición; (iii) incentivar procesos de transformación de practicas y de educación de los profesionales directamente vinculados al sistema; (iv) buscar, constantemente, formas de convergencia con iniciativas regionales.

b. Crear una estrategia de fortalecimiento de la capacidad institucional.

La actual capacidad instalada de las regiones es insuficiente y tiene deficiencias institucionales con respecto a MRV, lo que amerita la creación de capacidades y de fortalecimiento institucional para dichos propósitos. La forma, intensidad y contenido de las capacitaciones dependerá de los niveles de compromiso y ambiciones que REDD+ tenga.

c. Definir las amplitudes de intervención (de funciones) y responsabilidad de las instituciones estables en el tiempo que tengan a su cargo los inventarios forestales y el monitoreo de la deforestación y degradación.

La aplicación de REDD+ a nivel nacional es una actividad de largo plazo y, por lo tanto, requiere de información coherente, compatible, de largo plazo y medible en escala (UN-REDD 2009). Se deben definir las responsabilidades institucionales adecuadas, que permitan realizar las mediciones con el mayor control de calidad posible y busquen la integración de instituciones de otros niveles (local, regional y nacional). Los conflictos interinstitucionales dentro del Gobierno nacional, junto con las discrepancias entre los mandatos oficiales de los GORE y las fallas en la transferencia de capacidades de implementación (fiscales, humanas, etc.), crean una situación de urgencia frente a este tema.

d. Establecer sinergias en sistemas de monitoreo forestal existentes.

El marco institucional relacionado con el MRV debe facilitar la cooperación entre sectores. Los esfuerzos regionales y nacional de MRV de USCUSS y REDD+ deben tomar en consideración necesidades de información más allá del conteo del carbono como tal (UN-REDD 2009), buscando la sinergia con los sistemas de monitoreo forestal existentes. La integración actual entre el Proyecto REDD+ MINAM y el INF de FAO-MINAGRI-MINAM es un ejemplo de progreso frente la consolidación de estos esfuerzos.

e. Incrementar la colaboración entre las agencias estatales.

Uno de los mayores problemas para REDD+ en el Perú es la coordinación intersectorial (Menton et al. 2014). Existen propuestas para consolidar esta coordinación través de un órgano técnico para el monitoreo y se ven indicadores de mayor coordinación entre el MINAM y el MINAGRI, pero falta una decisión política de alto nivel para llevarlo a la práctica.

f. Promover una mayor participación de centros de investigación en el proceso de MRV.

Las universidades y los centros de investigación cuentan con gran cantidad de información a nivel local, por lo que se recomienda suscribir convenios con estos, que permitan determinar los temas prioritarios, identificando los nichos de oportunidad donde se pueden realizar investigaciones. Actualmente existen convenios con la Universidad de Maryland y el Instituto Carnegie, entre otras instituciones internacionales, pero falta aprovechar mejor los recursos disponibles en las universidades nacionales.

\section{Precondiciones económicas}

a. Realizar un análisis de las opciones de medición en diferentes escalas (de lo local a lo nacional). El costo de la implantación y manutención del sistema de MRV dependerá de: (i) el Nivel de precisión (Tier seleccionado) empleado en las mediciones y el monitoreo; (ii) la tecnología empleada (p. ej.: accesibilidad a imágenes); (iii) la 
escala (local, regional o nacional); (iv) el recurso humano disponible y el nivel de capacidades en las instituciones responsables; (v) la sinergia con otros sistemas y plataformas existentes; (vi) la disponibilidad de información (y metodología utilizada) de inventarios forestales que atienda a los propósitos del sistema de MRV. Se deben tomar en consideración los costos relacionados con las mediciones (validación) y la verificación de campo.

b. Determinar la exactitud y precisión de la intensidad de muestreo de acuerdo con el aporte de incentivos económicos esperado.

Para Wertz-Kanounnikoff et al. (2009), la exactitud es crucial para garantizar que las reducciones de emisiones no sean sobre- $\mathrm{o}$ subestimadas y que los pagos por los esfuerzos de reducción se realicen en forma adecuada. Un mayor nivel de exactitud requiere el uso de imágenes de alta resolución repetidas en el tiempo o imágenes que requieran de experiencia para su procesamiento; todas opciones que implican un costo.

\section{Precondiciones sociales/culturales}

a. Involucrar y fomentar la participación de todos los sectores (público y privado) en múltiples niveles.

El sistema de MRV debe considerar la inclusión social (pueblos indígenas y otros usuarios del bosque) para procesos participativos. La Ley de Consulta (Ley 29785) garantiza el derecho de consulta a los pueblos indígenas y por ello requiere la incorporación de un proceso de consulta a cualquier proyecto de REDD+, sea nacional o local. Los costos de transacción para permitir la participación de todos los interesados deben ser contabilizados en el diseño del sistema.

b. Determinar indicadores socioambientales que permitan evaluar los impactos proyectos/ programas/iniciativas y contribuir a salvaguardar los derechos de la población beneficiada y afectada.

La entidad/agencia ejecutora del sistema de MRV tiene, entre otras responsabilidades, las siguientes: (i) desarrollar y perfeccionar, permanentemente, metodologías e instrumentos de análisis, monitoreo y evaluación que incorporen criterios socioambientales; y (ii) observar las recomendaciones y restricciones de la zonificación ecológica económica (ZEE) cuando sea necesario. Dentro de lo posible, los indicadores deben estar alineados a las salvaguardas socioambientales internacionales. La
Alianza de Clima, Comunidad y Biodiversidad (CCB) certifica a los cobeneficios sociales y ambientales de los proyectos de mitigación de cambio climático.

c. Realizar diagnósticos de la situación socioeconómica y ambiental local antes del inicio de la implementación de las acciones de MRV propuestas.

La implementación y desarrollo de las acciones de REDD+ puede resultar en impactos negativos (sociales, económicos y ambientales) para la población/comunidad participante de la iniciativa, así como para las comunidades $\mathrm{y}$ regiones vecinas. Es fundamental que estos impactos sean monitoreados indirectamente en el sistema de MRV. El diagnóstico debe ser utilizado como referencia durante la etapa de implementación y evaluación del sistema y puede ser realizado teniendo en consideración drivers y agentes de deforestación y degradación de los bosques. Se recomienda evaluar las necesidades de información más allá de los datos socioeconómicos y biológicos colectados través del INF para crear sinergias entre estas iniciativas.

\section{Referencias}

Asencio Díaz, F. W. (2010). Tercer Plan Operativo Bienal. Zonificación Ecológica Económica y Ordenamiento Territorial 2011-2013. Informe Final. Dirección General de Ordenamiento Territorial. Ministerio del Ambiente. 62 pp. Asner GP, Knapp DE, Martin RE, Tupayachi R, Anderson CB, Mascaro J, Sinca F, Chadwick KD, Sousan S, Higgins M, Farfan W, Silman MR, Llactayo León WA, Neyra Palomino AF. 2014a. La geografía del carbono en alta resolución del Perú. Stanford, CA: Carnegie Institute y MINAM.

Asner GP, Knapp DE, Martin RE, Tupayachi R, Anderson CB, Mascaro J, Sinca F, Chadwick KD, Higgins M, Farfan W, Llactayo W, y Silman MR. 2014b. Targeting carbon conservation at national scales with high resolution monitoring. PNAS Early edition.

Baccini A.; S. J. Goetz, W. S. Walker, N. T. Laporte, M. Sun et al. (2012). Estimated carbon dioxide emissions from tropical deforestation improved by carbon-density maps. Nature Climate Change, 2(3): 182-185.

Calvo, Eduardo. 2008. Inventario Integrado de Emisiones de Gases de Efecto Invernadero del Perú en el año 2000. Informe preparado para 
el Ministerio del Ambiente en el marco del Proyecto "Segunda Comunicación Nacional del Perú a la Convención Marco de las Naciones Unidas sobre Cambio Climático". Noviembre 2008.

Capella, J. L. y M. Sandoval. 2009. Informe preliminar sobre aspectos jurídicos para el establecimiento de esquemas REDD en el Perú. Lima: Sociedad Peruana de Derecho Ambiental.

CDI e INDUFOR. (2012). Plan de Inversión Forestal. Componente III: Elementos para la identificación de áreas con mayor potencial para reducir emisiones de GEI en el sector forestal. Insumo para el Plan de Inversión Forestal de Perú, Fondo Estratégico sobre el Clima Programa de Inversión Forestal, Banco Interamericano de Desarrollo, Lima/Helsinki.

Chave, J.; C. Andalo, S. Brown, M. A. Cairns, J. Q. Chambers, D. Eamus, H. Folster, F. Fromard, N. Higuchi, T. Kira, J. P. Lescure, B. W. Nelson, H. Ogawa, H. Puig, B. Riera, T. Yamakura. 2005. Tree allometry and improved estimation of carbon stocks and balance in tropical forests. Oecologia, 145: 87-99.

Chave, J., M. Réjou Méchain, A. Búrquez, E. Chidumayo, M. S. Colgan, W. B. Delitti, A. Duque, T. Eid, P. H. Fearnside, R. C. Goodman, M. Henry, A. Martínez-Yrízar, W. A. Mugasha, H. C. Muller-Landau, M. Mencuccini, B. W. Nelson, A. Ngomanda, E. M: Nogueira, E. Ortiz-Malavassi et al. (2014). Improved allometric models to estimate the aboveground biomass of tropical trees. Global Change Biology, doi: $10.1111 / \mathrm{gcb} .12629$.

Che Piu, Hugo y García, Tania (2011) Estudio REDD Perú: La Situación de REDD en el Perú. DAR, RELADEFA, GIZ, Lima, Perú.

Che Piu H y Menton M. 2013. Contexto de REDD+ en Perú: motores, actores e instituciones. Documentos Ocasionales CIFOR 90. Bogor, Indonesia.

Escuela Formación Continua (EFC). 2011. Sistema de información y gestión ambiental. Sesión 1 . Guía del Capacitador/Facilitador "Identificación, Construcción y Análisis de Indicadores e Índices Ambientales". MINAM. $24 \mathrm{p}$

Feldpausch, T. R.; J. Lloyd, S. L. Lewis, R. J. W. Brienen, E. Gloor, A. M. Mendoza y T. R. Baker. (2012). Tree height integrated into pan-tropical forest biomass estimates. Biogeosciences, 9 (8): 3381-3403.

FAO. 2010. Global Forest Resources Assessment. FAO Forestry Paper 163. FAO: Roma, Italia.
FONAM. 2012. Peru Low Carbon Economy: Carbon projects, voluntary markets, REDD and NAMAs. FONAM: Lima, Perú.

Hansen MC, Potapov PV, Moore R, et al. 2013. High-resolution global maps of 21 st-century forest cover change. Science, 342(6160), 850-853.

Linares, C. 2011. Sistematización de Información sobre Los Recursos Forestales. Informe Final. Proyecto: FAO GCP/GLO/194/MUL. "Inventario nacional forestal y manejo forestal sostenible del Perú ante el cambio climático". Organización de las Naciones Unidas para la Agricultura y la Alimentación (FAO), Lima Perú.

Menton, M.; J. Perla, J. Sotes, L. Fatorelli. (2014). Análisis de las redes políticas de REDD+ en el Perú. CIFOR InfoBrief 87.

Meridian Institute. 2009. REDD+ Evaluación de Opciones Institucionales. Desarrollo de un marco institucional eficiente, efectivo y equitativo para REDD+ bajo el CMNUCC.

Ministerio de Agricultura (MINAG). 2009. Memoria Descriptiva del Mapa de Deforestación de la Amazonía Peruana 2000 Proyecto IM-03-02. 22 p.

MINAM. 2010. Mapa de Ámbito de Acción del Programa de Bosques. Disponible online: http://geoservidor.minam.gob.pe/geoservidor/ Archivos/Mapa/N01_PROGRAMA_ BOSQUES_2010.pdf

Ministerio del Ambiente (MINAM) 2010b. Segunda Comunicación Nacional del Perú a la CMNUCC. Lima, Perú. 208 p.

MINAM. 2010c. Mapa del Patrimonio Forestal Nacional 2010. Disponible online 4 de noviembre de 2014: http://geoservidor.minam. gob.pe/geoservidor/Archivos/Mapa/N21A PATRIMONIO_NATURAL_FORESTAL_ AMAZONIA_2010.pdf

Ministerio del Ambiente (MINAM). (2011a). Propuesta de Estrategia Nacional de Mitigación de Emisiones de Gases de Efecto Invernadero y criterios para su plan de acción. Documento de Trabajo del Grupo Técnico de Mitigación y MDL. Documento elaborado para la Segunda Comunicación Nacional del Perú a la CMNUCC. 49 pp. http://www.ibcperu.org/doc/ isis/12835.pdf

Ministerio del Ambiente (MINAM). (2011b). Plan de Acción de Adaptación y Mitigación frente al Cambio Climático.

Ministerio del Ambiente (MINAM). (2011c). Programa Nacional de Conservación de Bosques 
para la Mitigación del Cambio Climático (PNCBMCC). Segundo Informativo. 20 pp.

Ministerio del Ambiente (MINAM). (2012a). Presentación REDD+ MINAM. Taller de intercambio de información y trazado conjunto de la hoja de ruta para la implementación del mecanismo REDD+ en el Perú, 1 de febrero de 2012, Fondo de las Américas, Lima. 12 pp.

Ministerio del Ambiente (MINAM). (2012b). REDD+ Boletin. Reducción de Emisiones de la Deforestación y Degradación de los bosques. MINAM: Lima, Perú

Ministerio del Ambiente (MINAM). (2013). Readiness Plan Proposal RPP. Submitted to Forest Carbon Partnership Facility (FCPF).

MINAM. 2014a. Estrategia nacional ante el cambio climático. MINAM: Lima, Perú.

MINAM. 2014b. Emission Reductions Program Idea Note (ER-PIN), Peru. FCPF Carbon Fund.

MINAM 2014c. Estado situacional de la zonificación económica ecológica (ZEE) a nivel regional. Disponible online 4 noviembre de 2014: http://geoservidor.minam.gob.pe/geoservidor/ Archivos/Mapa/PROCESOS\%20DE\%20 ZEE\%20MARZO\%202014.pdf

MINAM. 2014d. Niveles de Referencia Forestal: ¿proyección de la tasa histórica promedio o la tendencia histórica? Presentación a taller informative con el Grupo REDD+, 4 de abril de 2014, Lima, Peru.

MINAM-DGOT. 2012. Mapa de deforestación en la Amazonía peruana al 2009. Lima, Perú: MINAM-DGOT.

MINAM-DGOT. 2013. Cambio de cobertura de bosque a no bosque por deforestación en la Amazonía peruana en el periodo 2009-20102011. Lima, Perú: MINAM-DGOT.

Mesa de Servicios Ambientales Regional - Madre de Dios (MSAR-MdD). 2014. Estimación de biomasa y mapa de carbono para MdD. Presentación disponible online 4 de noviembre de 2014: http://www.gruporeddperu.net/ MSAR19022014Sub_comis_Biomasa_ feb2014.pdf

Oliveira, P.; G. Asner, D. Knapp, A. Almeyda, R. Galván-Gildemeister, S. Keene, R. Raybin y R. Smith. (2007). Land-Use Allocation Protects the Peruvian Amazon. Science, 317, 1233-1236.
PLANCC. 2013. Actualización del inventario nacional de gases de efecto invernadero al año 2009. Disponible 18 de noviembre: http://www. planccperu.org/IMG/pdf/actualizacion_del_ inventario_29-08-2013.pdf

Saatchi, S. S.; N. L. Harris, S. Brown, M. Lefsky, E. T. A. Mitchard, W. Salas, B. R. Zutta, W. Buermann, S. L. Lewis, S. Hagen, S. Petrova, L. White, M. Silman y A. Morel. (2011). Benchmark map of forest carbon stocks in tropical regions across three continents. PNAS, 108(24): 9899-9904.

SIGMINAM. 2014. Concesiones mineras. Mapa disponible online 4 de noviembre de 2014: http:/geoservidor.minam.gob.pe/geoservidor/ Archivos/Mapa/N06_CONCESIONES_ MINERAS.pdf

SIGMINAM. 2013. Lotes de Contratos y Operaciones Petroleras. Mapa disponible 4 de noviembre de 2014: http://geoservidor.minam. gob.pe/geoservidor/Archivos/Mapa/N47_ LOTES_PETROLEROS.pdf

SIGMINAM. 2011. Megaproyectos. (mapa digital). The Forests Dialogue (TFD). (2009). Financiando los mecanismos REDD-plus. Una perspectiva de consenso del "The Forests Dialogue". Septiembre. 6 pp.

UN-REDD. (2009). Measurement, Assessment, Reporting and Verification (MARV) Issues and Options for REDD. Borrador de documento de discusión, marzo de 2009. 12 pp.

Vallejo, A. y P. Rodríguez-Noriega. (2008). Cuantificación de carbono en proyectos REDD. Curso internacional de diseño de actividades REDD para la mitigación del cambio climático. CATIE, Turrialba, Costa Rica. 51 pp.

Velarde, S. J.; G. Hyman, J. A. Marín, E. Barona. (2010). Causas de la deforestación y degradación $y$ deforestación futura en la Amazonía peruana. Reduciendo emisiones de todos los usos del suelo. Reporte para el Proyecto REALU-Perú. ICRAF Working Paper. Nairobi: World Agroforestry Centre, pp. 69-82.

Wertz-Kanounnikoff, S.; L. V. Verchot, M. Kanninen, D. Murdiyarso. (2008). How do we monitor, report and verify carbon emissions from forests? Capítulo 9: Moving ahead with REDD: Issues, options and implications. Angelsen, A. (ed.). CIFOR, Bogor, Indonesia, pp. 87-98. 
Perú está en la fase de elaboración de un sistema de MRV (medición reporte y verificación) para REDD+ (Reducción de Emisiones por la Deforestación y Degradación Forestal Plus) y USCUSS (Uso del Suelo, Cambio de Uso del Suelo y Silvicultura). Este resumen ejecutivo se presenta las informaciones ya existentes en el país con las precondiciones necesarias para un sistema MRV de USCUSS y REDD+ nacional que esté en armonía con las iniciativas y sistemas regionales.

\begin{tabular}{|c|c|c|}
\hline$\underbrace{\text { bj }}_{\text {CGIAR }}$ & $\begin{array}{l}\text { PROGRAMA DE } \\
\text { INVESTIGACION SOBRE } \\
\text { Bosques, Árboles y } \\
\text { Agroforestería }\end{array}$ & $\begin{array}{l}\text { Esta investigación fue realizada por CIFOR como parte del Programa de Investigación de CGIAR sobre } \\
\text { Bosques, Árboles y Agroforestería (CRP-FTA). El objetivo del programa es mejorar el manejo y uso de los } \\
\text { bosques, la agroforestería y los recursos genéticos de los árboles a lo largo del paisaje, desde bosques } \\
\text { hasta plantaciones. CIFOR dirige el programa CRP-FTA en asociación con Bioversity International, CATIE, } \\
\text { CIRAD, el Centro Internacional de Agricultura Tropical y el Centro Mundial de Agroforestería. }\end{array}$ \\
\hline
\end{tabular}

\section{cifor.org}

Fund ayudar en el diseño de políticas y prácticas que afectan a los bosques de los países en vías de desarrollo. CIFOR es un miembro del Consorcio CGIAR. Nuestra sede central se encuentra en Bogor, Indonesia, y contamos con oficinas en Asia, África y América Latina. 